Flood and Coastal Storm Damage Reduction Program

The Quantification and Evolution of Resilience in Integrated Coastal Systems

Martin T. Schultz, S. Kyle McKay, and Lyndell Z. Hales

August 2012

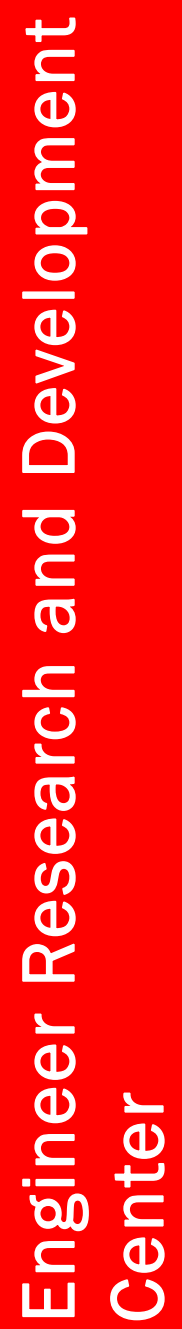




\title{
The Quantification and Evolution of Resilience in Integrated Coastal Systems
}

\author{
Martin T. Schultz and S. Kyle McKay \\ Environmental Laboratory \\ U.S. Army Engineer Research and Development Center \\ 3909 Halls Ferry Rd. \\ Vicksburg, MS 39180-6199 \\ Lyndell Z. Hales \\ Coastal and Hydraulics Laboratory \\ U.S. Army Engineer Research and Development Center \\ 3909 Halls Ferry Rd. \\ Vicksburg, MS 39180-6199
}

Final report

Approved for public release; distribution is unlimited

Prepared for U.S. Army Corps of Engineers

Washington, DC 20314-1000 


\section{Abstract}

Integrated coastal systems are designed, constructed, and maintained to achieve navigation, storm damage reduction, and ecosystem restoration objectives. This report develops a generally applicable method to quantify the resilience of integrated coastal systems to disturbances such as coastal storms. In general, resilience is an ambiguous term that can mean different things in different contexts. This report emphasizes engineering resilience, which is the propensity of a system to resist functional impairments as a result of a disturbance and to recover a pre-disturbance level of functional performance following a disturbance. This report describes how this property of integrated coastal systems can be quantified in probabilistic terms, and how the resilience of a system can evolve over time in response to gradual changes in boundary conditions that occur over time scales that are much longer than the disturbance of interest, such as gradual changes in mean sea level. Coastal system processes that are influenced by sea level rise and may affect the resilience of integrated coastal systems are identified. The advantages and disadvantages of probabilistic and non-probabilistic indicators of resilience are discussed.

DISCLAIMER: The contents of this report are not to be used for advertising, publication, or promotional purposes. Citation of trade names does not constitute an official endorsement or approval of the use of such commercial products. All product names and trademarks cited are the property of their respective owners. The findings of this report are not to be construed as an official Department of the Army position unless so designated by other authorized documents. 


\section{Contents}

Abstract................................................................................................................................... ii

Figures and Tables...........................................................................................................................iv

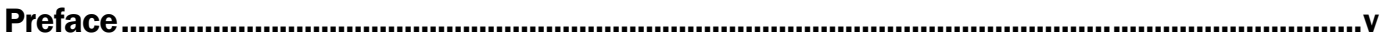

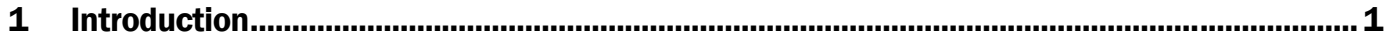

The definition and concept of resilience........................................................................ 2

Resilience in the context of USACE mission interests ............................................... 7

2 Quantifying Engineering Resilience ..................................................................................12

Systems, components, and processes ....................................................................... 12

Disturbances and evolutionary forces ..................................................................... 15

Resilience to disturbance ............................................................................................ 16

A general method to quantify resilience ......................................................................... 17

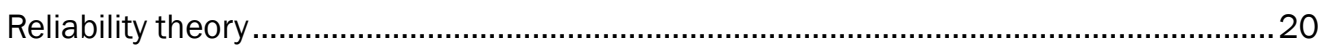

Robustness of subsystem components and processes................................................. 21

Functional dependence among subsystem components and processes .........................24

Rapidity of system components and processes ..............................................................26

Performance function for components and processes.................................................26

Resilience of subsystem components and processes ..................................................... 27

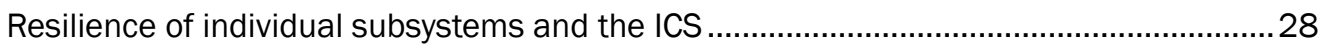

Evolution of resilience ...................................................................................................... 29

A step-by-step procedure for evaluating resilience in ICSs .......................................... 31

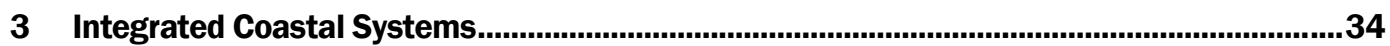

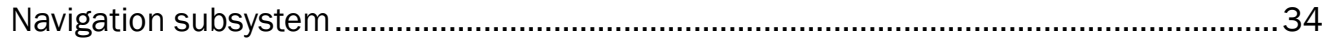

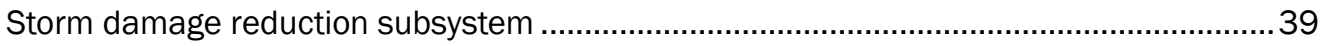

Ecological restoration subsystem ................................................................................. 40

4 Critical Processes Associated with Sea-level Rise that may Influence Resilience..............42

5 Non-probabilistic Indicators of Engineering Resilience .......................................................46

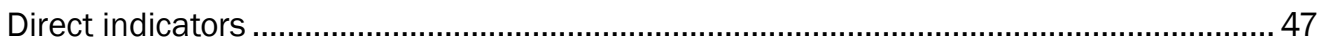



Critical levels for robustness and rapidity indicators ......................................................49

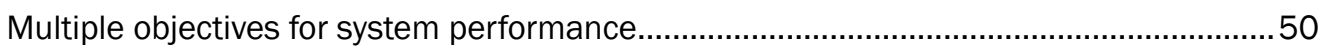

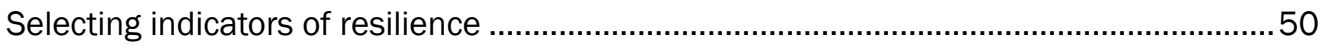

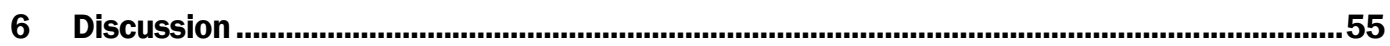

Advantages and disadvantages of probabilistic and non-probabilistic approaches ..........56

How could USACE use information about resilience? ................................................63

References........................................................................................................................................................67 


\section{Figures and Tables}

\section{Figures}

Figure 1. Components and processes of a generic ICS................................................................. 14

Figure 2. Resilience to a disturbance and the effect of an evolutionary force.................................. 17

Figure 3. Resilience and performance objectives........................................................................ 18

Figure 4. Regions of success and failure in the performance and recovery space........................... 19

Figure 5. Fragility curves for component and process function....................................................... 24

Figure 6. System resilience changes in response to an evolutionary force......................................30

\section{Tables}

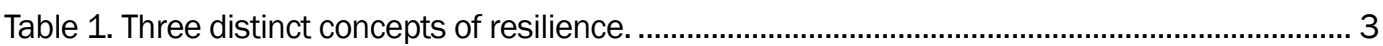

Table 2. Different types of resilience in different types of systems................................................. 5

Table 3. Components and processes that comprise the navigation subsystem. ................................35

Table 4. Components and processes that are part of the storm damage reduction

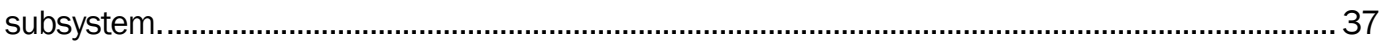

Table 5. Components and processes that are part of an ecosystem restoration subsystem defined by an oyster restoration project...............................................................................................38

Table 6. Effect of sea-level rise on components and processes of the navigation subsystem.

Table 7. Effect of sea-level rise on components and processes of the storm damage reduction subsystem.

Table 8. Desirable properties of metrics ............................................................................. 52

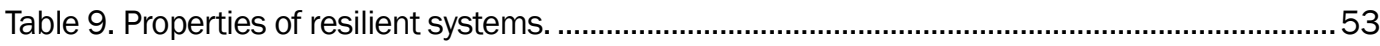

Table 10. Advantages and disadvantages of probabilistic and non-probabilistic approaches. 


\section{Preface}

This report develops a general method to quantify the resilience of integrated coastal systems that include both natural and engineered components. It describes the evolution of resilience in integrated coastal systems and identifies coastal system processes that may be influenced by sea-level rise and affect resilience.

This report was written by Dr. Martin T. Schultz, Environmental Risk Assessment Branch, Environmental Processes and Engineering Division (EPED), Environmental Laboratory (EL); Kyle McKay, Ecological Resources Branch, Ecosystem Evaluation and Engineering Division (EEED), EL; and Lyndell Z. Hales, Coastal and Hydraulics Laboratory (CHL) Technical Programs Office. A draft of this report was prepared in the spring of 2010 and distributed to participants in the Workshop on Quantification and Evolution of Resilience in Integrated Coastal Systems, held July 20-21, 2010, in Baltimore, Maryland. The authors gratefully acknowledge the participants in that workshop for insights and feedback on the draft report. This report was revised during fiscal year 2011 and distributed for external peer review in January 2012. The manuscript was reviewed by Dr. Thomas D. O'Rourke, Cornell University, College of Engineering, School of Civil and Environmental Engineering and by Dr. Seth D. Guikema, Johns Hopkins University, Whiting School of Engineering, Department of Geography and Environmental Engineering. The authors gratefully acknowledge the service of these reviewers as well as the comments and insights they provided to help improve the report.

This report was written under the direct supervision of Dr. Beth C. Fleming, Director, EL; and Dr. William Martin, Director, CHL. Warren P. Lorentz was Chief of the EPED, EL and Buddy L. Goatcher was Chief of the Environmental Risk Assessment Branch, EL. William R. Curtis was Technical Director, Flood and Coastal Storm Damage Reduction Program.

COL Kevin J. Wilson was Commander of the ERDC. Dr. Jeffery P. Holland was Director of the ERDC. 


\section{Introduction}

The U.S. Army Corps of Engineers (USACE) has a mission interest in planning, designing, constructing, and managing flood control, navigation, and ecosystem restoration projects as an integrated system. An integrated coastal system (ICS) is engineered to meet specific performance objectives and to maintain a functional level of performance in the face of short-term disturbances such as coastal storms. In addition, these systems should maintain the level of performance for which they were designed in the face of gradual changes in environmental and other boundary conditions, such as sea-level rise. A better understanding of techniques for quantifying, evaluating, and improving the resilience of coastal systems is needed to support this mission interest.

Resilience is the ability of a system to maintain and/or recover its functional performance following a disturbance. This property of resilience may evolve as environmental and other boundary conditions change over time. Interest in the characterization and management of resilience in coastal systems has increased in recent years (Adger et al. 2005; National Research Council (NRC) 2009; Fagre et al. 2009). This interest has been prompted by the occurrence of several severe storm events that have had notable impacts on the functionality of coastal systems and the safety of coastal residents. Interest has been further heightened by projections of global sea-level rise that presently range between 0.4 to $4.9 \mathrm{ft}$ per century (Titus et al. 2009). Changes in sea level may affect the resilience of coastal systems, but there is limited understanding of how significant these impacts might be and how they might be evaluated.

The objectives of this report are as follows: 1) summarize the state of the science with respect to the definition and quantification of resilience, 2) develop a general method to characterize resilience and the effect of sea-level rise on resiliency quantitatively, 3) describe what is meant by the term "evolution of resilience" and what factors might affect the resilience of coastal systems, 4) describe how coastal system resilience might be influenced by sea-level rise and how the effects of sea-level rise on resiliency might be assessed, and 5) describe how resiliency might be classified or indexed to different objectives. 
The outline of this report is as follows: The remainder of Chapter 1 introduces the concept of resilience and discusses its meaning in the context of USACE's mission interests. Chapter 2 develops a general method to quantitatively characterize resilience and the effect of sea-level rise on resilience in ICSs using a probabilistic approach. Chapter 2 concludes with a discussion of what is meant by the term "evolution of resilience." Chapter 3 identifies the components and processes of ICSs. Chapter 4 describes how sea-level rise might affect the resilience of individual components and processes. Chapter 5 describes how nonprobabilistic indicators of resilience might be developed as an alternative to probabilistic measures of resilience. Chapter 6 compares probabilistic measures and non-probabilistic indicators of resilience and discusses how these might be used with respect to different objectives or functions within the agency.

\section{The definition and concept of resilience}

The resilience of a material is its ability to store strain energy and deflect elastically under a load without breaking or being deformed (Gordon 1978, Klein et al. 2003). Since the 1970's, the term has also been used to describe the ability of a system to absorb an external shock and recover its predisturbance condition (Klein et al. 2003). Despite nearly four decades worth of research on the concept of resilience in systems, there is still much confusion about the meaning of the term and no common understanding regarding how resilience should be quantified. In addition, it is not always clear whether or not resilience is a conceptual way of thinking about change within a system, a specific property of a system that can be observed or estimated, or a goal that should be managed for and achieved (Klein et al. 2003). The various perspectives on resilience in the literature can be grouped into three major categories, outlined below (Wang and Blackmore 2009). These three major types of resilience are further described in Table 1.

- Ecological resilience describes the ability of a natural, self-organizing system to absorb change and disturbance and remain in the same state, meaning that the relationships among populations and state variables are maintained so that the system retains the same functions, structure, and feedbacks (Holling 1973, Walker et al. 2006, Brand and Jax 2007). Quantitative measures of resilience have been described in theory, but have not been estimated in practice. A quantitative measure of ecological resilience describes the amount of a force that would cause a system to reorganize itself into an alternate state (Holling 1973). The difficulty of 
quantifying resilience in ecological systems can be attributed to the difficulty of determining the thresholds at which organization into a new state would occur.

Table 1. Three distinct concepts of resilience.

\begin{tabular}{|l|l|l|l|l|}
\hline $\begin{array}{l}\text { Resilience } \\
\text { Concept }\end{array}$ & Definition & Emphasis & $\begin{array}{l}\text { Quantitative } \\
\text { Measures }\end{array}$ & $\begin{array}{l}\text { Estimation of } \\
\text { Measures }\end{array}$ \\
\hline $\begin{array}{l}\text { Ecological } \\
\text { resilience }\end{array}$ & $\begin{array}{l}\text { The ability to resist } \\
\text { being forced into an } \\
\text { alternate state. }\end{array}$ & $\begin{array}{l}\text { How the system } \\
\text { functions are } \\
\text { performed. }\end{array}$ & $\begin{array}{l}\text { The force needed } \\
\text { to push a system } \\
\text { into an alternate } \\
\text { steady state. }\end{array}$ & $\begin{array}{l}\text { Theoretical. Not } \\
\text { estimated in } \\
\text { practice because of } \\
\text { uncertainty in } \\
\text { thresholds. }\end{array}$ \\
\hline $\begin{array}{l}\text { Engineering } \\
\text { resilience }\end{array}$ & $\begin{array}{l}\text { The ability to resist } \\
\text { and recover from } \\
\text { disturbance. }\end{array}$ & $\begin{array}{l}\text { Functional } \\
\text { performance. }\end{array}$ & $\begin{array}{l}\text { Functions of the } \\
\text { rate at which pre- } \\
\text { disturbance } \\
\text { performance levels } \\
\text { are recovered. }\end{array}$ & $\begin{array}{l}\text { Quantified in } \\
\text { practice using } \\
\text { simulation models } \\
\text { or data on past } \\
\text { performance. }\end{array}$ \\
\hline $\begin{array}{l}\text { Community } \\
\text { resilience }\end{array}$ & $\begin{array}{l}\text { The ability to } \\
\text { mishaps in } \\
\text { organizations } \\
\text { through learning } \\
\text { and adaptation. }\end{array}$ & $\begin{array}{l}\text { The ability to adapt, } \\
\text { reorganize, or } \\
\text { develop new } \\
\text { functions specifically } \\
\text { conditioned on the } \\
\text { disturbance. }\end{array}$ & $\begin{array}{l}\text { None known. } \\
\text { distand avoid }\end{array}$ & $\begin{array}{l}\text { Conceptual. Not } \\
\text { estimated } \\
\text { quantitatively. }\end{array}$ \\
\hline
\end{tabular}

- Engineering resilience describes the ability of a system to maintain functional performance in the face of a disturbance and/or return to its pre-disturbance performance level following a disturbance (Hashimoto et al. 1982a, Moy et al. 1986, Maier et al. 2001, Chang and Shinozuka 2004, Wang and Blackmore 2009). This conceptualization is appropriate for evaluating engineered systems because the goal of such systems is to achieve constancy and predictability in functional performance (Holling 1996, Wang and Blackmore 2009). Engineering resilience is generally seen as a property of a system that can be measured or estimated. A wide variety of quantitative measures of engineering resilience have been proposed (e.g., Hashimoto et al. 1982b, Fiering 1982a, 1982b, 1982c; Moy et al. 1986; Maier et al. 2001; Chang and Shinozuka 2004; Simonovic and Li 2004; Reed et al. 2009), but there appears to be no agreement among practitioners as to how engineering resilience should be quantified.

- Community resilience is the ability of organizations and human communities to learn and adapt in ways that preempt and avoid major mishaps that would otherwise disrupt their missions (Wang and Blackmore 2009). In this context, resilience describes the ability of an organization or community to adapt by developing new functions in 
response to disturbances (Martin-Breen and Anderies 2011). Chang et al. (2008) and Renschler et al. (2010) have made progress incorporating information about community resilience into studies that assess the resilience of lifeline infrastructure to earthquakes. However, the authors of this report are unaware of any literature that attempts to quantify the ability of a community to transform and adapt new functions in response to a disturbance.

Several authors have discussed differences in definitions of resilience (Holling 1996, Brand and Jax 2007, Wang and Blackmore 2009). For example, Holling (1996) discusses the distinctions between engineering resilience and ecological resilience and describes how these differences can be attributed to differences in prevailing world views within the disciplines from which they originate. In engineering, the objective is to obtain efficiency, constancy, and predictability through fail-safe design and to maintain stability near an equilibrium steady state. Thus, the engineering resilience of a system is measured by the system's ability to recover to its pre-disturbance equilibrium state. In contrast, the ecological world view recognizes that natural systems are self-organizing and can somehow adapt to external pressures while still performing their functions such as ecological services and productivity. Therefore, ecological resilience is often defined as the "ability of a system to absorb disturbance and still retain its basic function and structure" (Walker and Salt 2006). Social scientists tend to see communities as self-organizing systems that are capable of functioning in alternative equilibrium states and, therefore, social scientists tend to adopt a view of resilience that is similar to that of ecologists (e.g., Adger et al. 2005). Community or social resilience considers the role that factors such as communication, organizational learning, and adaptive management may have on the ability of a social organization to avoid losses from accidents, mistakes, and other types of disturbances (Wang and Blackmore 2009). This concept emphasizes the capacity of a community or social organization to transform itself by reorganizing and developing new ways of functioning that are specifically conditioned on the disturbance (Martin-Breen and Anderies 2011).

Each resilience concept is uniquely adapted to describe different types of systems. Ecological resilience seems most appropriate to describe natural, self-organizing systems, engineering resilience seems most appropriate to describe engineered systems, and community resilience seems most appropriate to describe social systems (e.g., organizations). However, 
examples of each type of resilience can be found in each of the different types of systems that are described here. Table 2 illustrates how each type of resilience might be demonstrated in natural, engineered, and social systems. Quantitative measures of resilience proposed in this table differ across the three different types of resilience because each type of resilience describes a different quality or characteristic. Thus, if one is interested in measuring the ecological resilience of a natural, engineered, or social system, one would focus on quantifying the strength of the disturbance that would cause a state change. To measure the engineering resilience of a natural, engineered, or social system, one could quantify the rate at which pre-disturbance performance levels are restored. If one were interested in measuring the community resilience of a natural, engineered, or social system and could devise a way to quantify the ability to transform and adapt by developing new functions, this characteristic could be measured in every type of system: natural, engineered, and social.

Table 2. Different types of resilience in different types of systems.

\begin{tabular}{|c|c|c|c|c|c|}
\hline $\begin{array}{l}\text { System } \\
\text { Type }\end{array}$ & System & $\begin{array}{l}\text { Nature of } \\
\text { Disturbance }\end{array}$ & $\begin{array}{l}\text { Type of } \\
\text { Resilience }\end{array}$ & $\begin{array}{l}\text { How Resilience Type is } \\
\text { Demonstrated }\end{array}$ & $\begin{array}{l}\text { Quantitative Measure } \\
\text { of Resilience }\end{array}$ \\
\hline \multirow{3}{*}{ Natural } & \multirow{3}{*}{ Tidal wetland } & \multirow{3}{*}{ Coastal storm } & Ecological & $\begin{array}{l}\text { Tidal wetland recovers } \\
\text { following a storm that } \\
\text { created favorable } \\
\text { conditions for the } \\
\text { transition to a mudflat or } \\
\text { open water system. }\end{array}$ & $\begin{array}{l}\text { The strength of the } \\
\text { storm needed to } \\
\text { cause erosion or } \\
\text { other conditions } \\
\text { favorable for a state } \\
\text { transition. }\end{array}$ \\
\hline & & & Engineering & $\begin{array}{l}\text { The biomass of the plant } \\
\text { community is reduced by a } \\
\text { storm, but the community } \\
\text { recovers pre-disturbance } \\
\text { levels of primary } \\
\text { production. }\end{array}$ & $\begin{array}{l}\text { The rate at which } \\
\text { primary productivity } \\
\text { returns to its former } \\
\text { levels. }\end{array}$ \\
\hline & & & Community & $\begin{array}{l}\text { Benthic organisms (e.g. } \\
\text { oysters) bury themselves } \\
\text { in sediment as the storm } \\
\text { approaches to prevent } \\
\text { being washed away. }\end{array}$ & None. \\
\hline \multirow{2}{*}{ Engineered } & \multirow{2}{*}{$\begin{array}{l}\text { Municipal } \\
\text { water } \\
\text { distribution } \\
\text { system }\end{array}$} & \multirow{2}{*}{ Drought } & Ecological & $\begin{array}{l}\text { The municipality imports } \\
\text { treated water to meet } \\
\text { water demand. }\end{array}$ & $\begin{array}{l}\text { The severity of the } \\
\text { drought that would } \\
\text { lead to restrictions } \\
\text { on water use. }\end{array}$ \\
\hline & & & Engineering & $\begin{array}{l}\text { Water levels in the } \\
\text { reservoirs increase to pre- } \\
\text { drought levels following } \\
\text { the drought. }\end{array}$ & $\begin{array}{l}\text { The rate at which } \\
\text { target water levels } \\
\text { are restored following } \\
\text { the drought. }\end{array}$ \\
\hline
\end{tabular}




\begin{tabular}{|c|c|c|c|c|c|}
\hline $\begin{array}{l}\text { System } \\
\text { Type }\end{array}$ & System & $\begin{array}{l}\text { Nature of } \\
\text { Disturbance }\end{array}$ & $\begin{array}{l}\text { Type of } \\
\text { Resilience }\end{array}$ & $\begin{array}{l}\text { How Resilience Type is } \\
\text { Demonstrated }\end{array}$ & $\begin{array}{l}\text { Quantitative Measure } \\
\text { of Resilience }\end{array}$ \\
\hline & & & Community & $\begin{array}{l}\text { Municipality implements a } \\
\text { program to educate } \\
\text { customers about water } \\
\text { conservation. }\end{array}$ & None. \\
\hline \multirow{3}{*}{ Social } & \multirow{3}{*}{ Corporation } & \multirow{3}{*}{$\begin{array}{l}\text { Abrupt shift in } \\
\text { consumer } \\
\text { preference }\end{array}$} & Ecological & $\begin{array}{l}\text { Corporation adapts } \\
\text { products to maintain } \\
\text { profitability and avoid } \\
\text { reorganization. }\end{array}$ & $\begin{array}{l}\text { The change in } \\
\text { consumer preference } \\
\text { that would force the } \\
\text { corporation to } \\
\text { reorganize and } \\
\text { develop new } \\
\text { products. }\end{array}$ \\
\hline & & & Engineering & $\begin{array}{l}\text { Profit levels prior to the } \\
\text { shift in consumer } \\
\text { preference are restored } \\
\text { following the adaptation of } \\
\text { products. }\end{array}$ & $\begin{array}{l}\text { The rate at which } \\
\text { profitability is } \\
\text { restored to former } \\
\text { levels. }\end{array}$ \\
\hline & & & Community & $\begin{array}{l}\text { Corporation implements } \\
\text { communication plan to } \\
\text { continuously monitor } \\
\text { consumer preferences. }\end{array}$ & None. \\
\hline
\end{tabular}

The quantitative measures proposed in Table 2 differ across the three types of resilience because each type of resilience describes a different quality of a system. These qualities can be found to a greater or lesser extent (or not at all) in every imaginable system. For example, a tidal wetland is a natural system that may be disturbed by coastal storm events. The qualities of ecological, engineering, and community resilience are exhibited within that system. The system exhibits ecological resilience when it resists transitioning to become a mudflat or open water. This characteristic of ecological resilience can be quantified as the strength of the storm that would force the wetland into one of these alternate states. A tidal wetland can also demonstrate engineering resilience. For example, the storm could cause damage to plants, reducing plant biomass and primary productivity. If primary productivity is used as a measure of the system's functional performance, engineering resilience is demonstrated when biomass is restored and primary productivity increases to pre-storm levels. Community resilience is demonstrated in a natural system when that system adapts to prevent potential losses associated with the disturbance. In this case, the example focuses on benthic organisms, which are a component of the tidal wetland system. Some benthic organisms have the ability to take shelter from coastal storms by burying themselves deeper into the mud. This ability to avoid the effects of the disturbance by adapting to change might be considered an example of community resilience, as defined in Table 1. 
Different types of resilience can be found and measured in different types of systems. Understanding that the three major concepts of resilience describe distinctly different characteristics of systems and that these characteristics can be observed in different types of systems may help to resolve the ambiguity that pervades the literature on resilience. However, for any one of the three resilience concepts described here, many more definitions of resilience can be found (Brand and Jax 2007, Zhou et al. 2010) and, according to Brand and Jax (2007), confusion over the meaning of the term is increasing. Therefore, it is important to be as precise as possible when discussing the topic of resilience. Before beginning an analysis of resilience in a system, several questions must be answered:

- What type of system is the subject of analysis and what is the disturbance of interest?

- What are the motivations for and objectives of the analysis?

- What decisions will be made based on the analysis and who is the decision maker?

Different definitions of resilience will be more or less appropriate given the context and motivations of an analysis. The concept of resilience that is chosen for a given purpose must be appropriate to both the purpose of the study and the system under investigation. For example, consider a system comprised of bricks and mortar that is designed to perform a specific function. A quantitative measure of the engineering resilience could provide useful information that can be used in making management decisions about that system. In contrast, it would seem to make no sense to measure the community resilience of a bricks and mortar system because such a system is clearly incapable of transformation and adaptation.

\section{Resilience in the context of USACE mission interests}

The USACE mission interests with respect to coastal systems can be described in terms of three performance objectives:

- Navigation: Provide safe, reliable, and efficient waterborne transportation within coastal, estuarine, and riverine systems (Rosati and Kraus 2009).

- Storm damage reduction: Protect coastal communities from economic loss as a result of exposure to coastal storms and surface water runoff. 
- Ecosystem restoration: Restore degraded habitats to a condition that approximates a pre-disturbance condition, or to a less degraded, more natural condition that will sustain healthy and diverse biotic communities.

While coastal systems often incorporate natural components and processes, the three primary performance objectives cannot typically be met unless the coastal system is engineered to achieve them. If the objective in designing and managing coastal systems is to maintain constancy and predictability in system function consistent with original design objectives, then it seems that engineering resilience is a more useful measure of system resilience than the other forms of resilience described in Table 1. There are implications associated with characterizing the objectives of an ICS in terms of navigation, storm damage reduction, and ecosystem restoration. Three issues need to be considered in evaluating these implications. These are the objectives of the ICS, the definition of the ICS, and the measure chosen to evaluate resilience.

The definition of the ICS described above is limited to encompass infrastructure sub-systems that are designed to achieve a limited number of objectives that are clearly within the purview of the USACE. The decision to limit the ICS to these subsystems can be explained by a desire to focus the agency's resources on addressing problems over which the agency has the greatest control. In reality, however, ICSs are much more complex, and consist of many more subsystems that serve a much more diverse set of objectives than are outlined here. Ultimately, and ideally, all of these subsystems support the common goal of having safe, happy, healthy, and productive human communities in coastal areas. Therefore, it should be understood that information about the resilience of the navigation, storm damage reduction, and ecosystem restoration subsystems alone can provide only a limited perspective on the resilience of the larger ICS of which they are a part.

In decision sciences, two basic types of objectives are recognized: means objectives and fundamental objectives. A means objective exists solely because it is a means to an end - that is, achieving the means objective somehow facilitates the attainment of a more important or grander fundamental objective. A fundamental objective is the objective that is ultimately desired. The distinction is important because making decisions based on an optimization of means objectives can lead to outcomes that 
are sub-optimal with respect to the fundamental objectives. Similarly, an evaluation of the means objective provides only a limited perspective in terms of evaluating what progress has been made towards a fundamental objective. Thus, while it is necessary to manage for a means objective in order to achieve a fundamental objective and it is useful to evaluate progress toward means objectives, information about progress toward those objectives is not sufficient for decision making.

Navigation, storm damage reduction, and ecosystem restoration objectives can be considered means to achieving the fundamental objective of having safe, happy, healthy, and productive human communities in coastal areas. Therefore, understanding the engineering resilience of navigation, storm damage reduction, and ecosystem restoration infrastructure is necessary, but not sufficient for fully understanding the resilience of coastal systems that include human communities. To fully understand the resilience of a coastal system that incorporates coastal human communities, a broader set of performance objectives with respect to sustaining those communities would need to be taken into account. This could be accomplished by expanding the boundaries of analysis to include the full scope of lifeline infrastructure and functions that are somehow dependent upon coastal infrastructure, the economic and social consequences of infrastructure failure and storm damage, and the social and human factors that influence a community's response to disturbances.

Defining the coastal system adopted in this report could have been approached in at least two different ways. One approach would have been to include the organizations responsible for designing, constructing, operating, and maintaining the navigation, storm damage reduction, and ecosystem restoration subsystems as an integral part of the coastal system. Had this approach been taken, it might have been appropriate to consider the adaptive capacity of the coastal system, which then would have involved considering the organizational behavior and the institutional and practical constraints those actors face in terms of responding to disturbances in real time and making investments to modify or update existing infrastructure to achieve navigation, storm damage, and ecosystem restoration objectives. Yet another approach would have been to define the coastal system to also include the human communities that are somehow dependent on the navigation, storm damage reduction, and ecosystem restoration subsystems in addition to the organizations that are responsible for designing, building, operating, and maintaining those subsystems. This approach would have 
led to a much more comprehensive evaluation of the consequences of disturbances and the factors that influence the response to those disturbances.

By including actors or self-organizing systems as part of the system, it would have been possible to measure resilience, either in terms of engineering resilience or community resilience. Engineering resilience is measured in terms of losses in the quality of system performance and/or the length of time required to restore a pre-disturbance quality of performance. In contrast, community resilience is measured in terms of the ability of a selforganizing system to adapt to occasional disturbances by developing new functions that are specifically conditioned on those disturbances. The difference in these measures of resilience is that engineering resilience focuses on performance and community resilience focuses on adaptive capacity, which is a factor that influences performance. A full understanding of the resilience of a self-organizing system can only be achieved by considering both engineering resilience and community resilience.

Framing an evaluation of resilience in terms of community resilience rather than engineering resilience drastically changes the nature of the analysis. Technical issues of structural and functional reliability become less important and social, political, and psychological issues become much more important. For example, Chang et al. (2008) and Renschler et al. (2010) incorporate information about both engineering resilience and community resilience in studies that develop approaches to assessing the resilience of human communities to earthquakes. According to Renschler et al. (2010), an assessment of a community's adaptive capacity should include an evaluation of community competence and social-cultural capital. Community competence is a function of collaborative relationships, problem-solving skills, flexibility, creativity, efficacy, empowerment, and political partnerships (Norris et al. 2008, in Renschler et al. 2010). Social-cultural capital is a function of leadership, vision, stakeholder participation, and optimism (Renschler et al. 2010).

In the present study, the decision to define the coastal system in terms of navigation, storm damage reduction, and ecosystem restoration infrastructure and functions related to core USACE mission objectives has influenced the approach proposed for evaluating coastal system resilience. This technical report emphasizes engineering resilience because the coastal system as defined here has no self-organizing or adaptive capability. 
Information about the engineering resilience of these subsystems is necessary for understanding the resilience of the larger coastal communities of which they are a part. However, this focus on navigation, storm damage reduction, and ecosystem restoration infrastructure should not be interpreted as a suggestion that other subsystems are somehow unimportant or that aspects of resilience other than engineering resilience should not be investigated. The methods and ideas that are presented in this technical report can be extended, modified, and adapted to help develop a comprehensive understanding of the resilience of coastal systems at various scales and consisting of a wide variety of components and processes. 


\section{Quantifying Engineering Resilience}

\section{Systems, components, and processes}

The method to quantify resilience described in this report is general in the sense that it could be applied to many different types of systems. A system is a set of components and processes that work in concert with one another to perform a specific function. The components of a system are the set of physical features that support the function, including manmade and natural features. The processes of a system are the set of sustained physical, chemical, and biological phenomena that occur within the designated boundaries of the system and contribute to its function. The components and processes of a system can be identified by first identifying a function of interest, establishing boundaries for that system, and then analyzing how a function is performed within those boundaries.

Over the past decade, the USACE has taken significant steps toward introducing a systems approach in planning, designing, and constructing projects in coastal systems to achieve the greatest possible return on national investment. A systems approach helps to ensure the maximum return on investment by utilizing one or more features of the coastal system to achieve two or more functional performance objectives simultaneously. An ICS is defined as one in which the functional performance of navigation, storm damage reduction, and ecosystem restoration systems are linked by a dependency on at least one common component or process. These linkages may be direct or indirect:

- Direct: A direct linkage means that the output or function of one mission area actively provides an input to or serves as a component of another mission area. For example, maintenance dredging of a navigation channel may provide sediment for use in a beach nourishment project that helps to maintain the level of storm damage reduction and increase the extent of coastal wetlands.

- Indirect: An indirect linkage is exemplified by a system in which the functions depend upon common components and processes. For example, a jetty acting as a component of a navigation system may create local currents that result in an increase in the rate at which sand is deposited on a target beach, enabling a process of natural shoreline accretion and preventing migration of the shoreline inland. 
When shared components or processes fail to perform as intended, this may affect the functional performance of two or more mission areas.

A system may be engineered, natural, or human. Natural systems are self organizing. An ecological community is an example of a self-organizing natural system. While they are not designed by man to perform a specific function, natural systems may perform a useful function. For example, an estuary is a natural system that provides habitat for fish in their early life stages and functions to provide economic benefits in the form of commercial and sport fisheries. In contrast, engineered systems are designed and constructed by man to perform a specific function. Engineered systems may incorporate natural components by design. For example, a navigation system may consist of navigation channels, jetties, and port infrastructure that are man-made and may also incorporate naturally occurring bays and rivers. Human systems are those in which humans or groups of humans act as components and the interactions among humans or groups of humans are important to the overall functional performance of the system. Communities and organizations are examples of human systems.

A system may be closed or open. A closed system is one in which the components and processes are not affected by forces external to the system. An example of a closed system is an electrical circuit. An open system is one in which environmental forces act on components or processes, potentially altering their respective states and affecting the functional performance of the system. An ecological community is an example of an open system. Its components are exposed to and respond to environmental forces such as temperature and rainfall. Collectively, these external variables influence the state or condition of internal components and processes and may affect the functional performance of the system.

An integrated coastal system is classified as an open, engineered system. The system consists of three subsystems, including the navigation subsystem, the storm damage reduction subsystem, and the ecosystem restoration subsystem. Each subsystem has at least one function. For example, the navigation subsystem provides access to ports and harbors. The storm damage reduction subsystem reduces the costs associated with property damage from coastal storms. The ecosystem restoration subsystem restores degraded habitats. The overall function of each subsystem depends on the functional performance of a set of components and processes that support subsystem function. For example, the navigation subsystem is 
supported by several components (navigation channels, turning basins, jetties, dredged material disposal sites) and processes (dredging and sediment runoff). Each subsystem functions when the components or processes upon which it depends function as intended.

Figure 1 breaks down a generic ICS to show how the subsystem functions of that ICS might be jointly dependent upon shared components and processes. Three distinct subsystems are identified in the figure (navigation, storm damage reduction, and ecosystem restoration). Each subsystem is supported by a set of components or processes. Where a component or a process supports more than one subsystem, the box denoting that component or process spans the boundaries of the subsystem. For example, wetlands may serve a storm damage reduction function by dissipating wave energy and an ecosystem restoration function by sustaining healthy and diverse aquatic communities. Therefore, the wetland box overlaps the subsystem boundaries for storm damage reduction and ecosystem restoration. Similarly, estuaries support all three ICS functions and overlap all three subsystem boundaries. The components and processes included in Figure 1 are illustrative and designed simply to show how different components and processes might be related to two or more ICS subsystems. Chapter 3 describes a broader array of components and processes that support the function of each ICS subsystem. The boundary conditions in Figure 1 are the set of internal and external forces that are acting on the components and processes and affect their function. External forces include wind, waves, tides, currents, rainfall, barometric pressure, and other such environmental forces. Examples of internal forces might include age, rust, or corrosion.

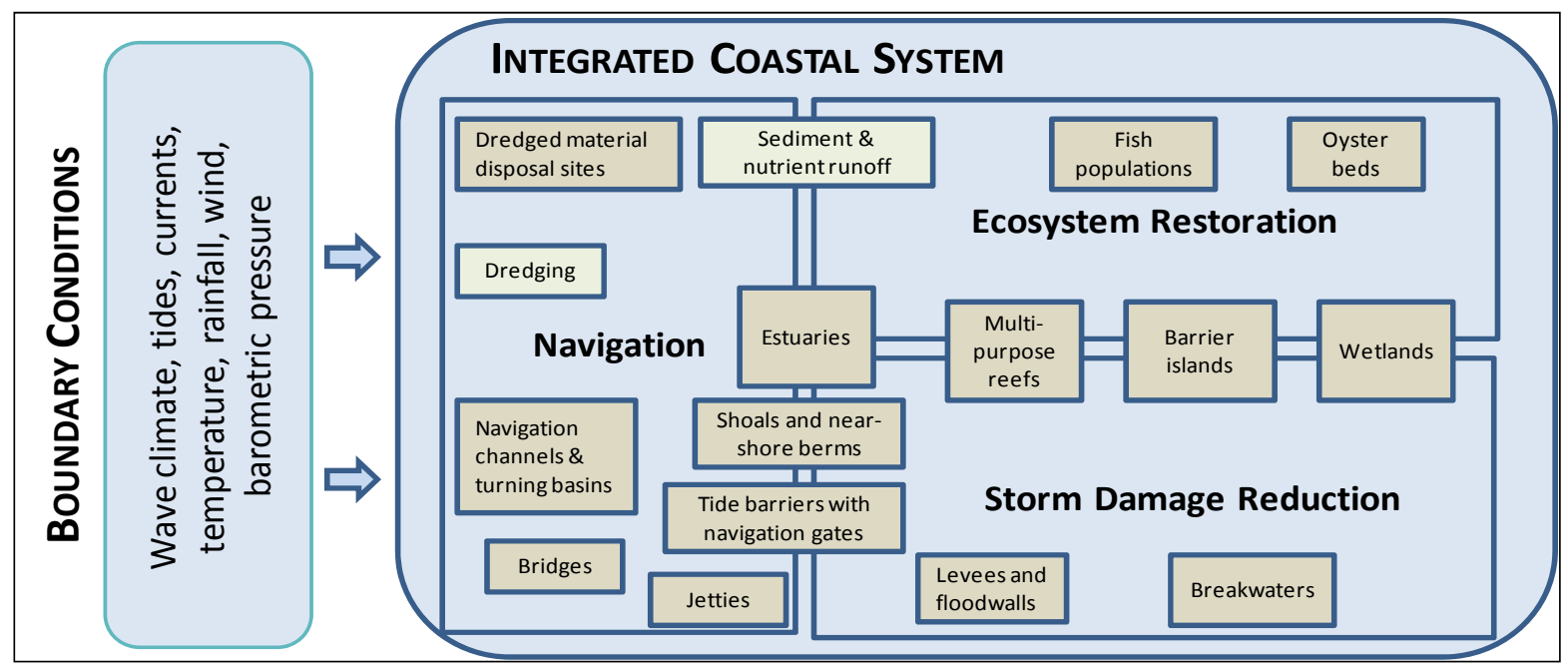

Figure 1. Components and processes of a generic ICS. 
An ICS achieves optimal performance when the system components and processes function as designed. The functional performance of system components and processes can be disrupted by forces that are internal or external to the system. For example, the functional performance of a navigation system may be impaired because the hinges on the navigation gate in a tide barrier have deteriorated or because river flows have dropped below a point at which navigation is possible. The former is an example of an internal system component failure. The latter is an example of an external or environmental force acting on the component or process to cause failure. External forces often transcend the spatial and temporal boundaries of the system. For example, the low flows in a river may be the result of regional drought induced by an El Nino event that occurred halfway around the world six months prior. Deviations of boundary conditions from their design states may cause component and process failures, resulting in sub-optimal system performance.

There may be many ways of characterizing a system in terms of identifying its boundaries and its components or processes and choosing the resolution at which to represent components and processes. For example, fish are a biological component of aquatic ecosystems and may be understood in terms of individuals, schools, populations, or trophic classes. Navigation gates are a physical component of navigation systems and may be understood as a single entity within a navigation system or as a subsystem comprised of foundations, walls, doors, and motors. The appropriate level of resolution for an analysis of the system simply depends upon the function of interest and how the components and processes interact to perform that function. No one way is necessarily correct, but some ways will be more useful than others. What constitutes a useful way of characterizing a system will depend on the purpose and objectives of a resilience analysis.

\section{Disturbances and evolutionary forces}

A disturbance is a short-term or transient excursion of forces acting on system components and processes in ways that may impair system function. A disturbance is synonymous with an extreme event, which has been defined as a boundary condition state that has a low probability of occurrence and that may lead to severe consequences and catastrophic losses (Stewart and Bostrom 2002, McDaniels et al. 2008). Disturbances may be internal or external. An example of an internal disturbance might be the sudden failure of a hinge on the gate in a navigable storm barrier that prevents the passage of ships through a navigation system. An example of 
an external disturbance is a coastal storm. Following a disturbance, recovery to a pre-disturbance performance level may be possible, but effort may be required to restore the function of system components and processes that may have been damaged as a result of the disturbance.

An evolutionary force is a gradual and persistent change in boundary conditions that may affect the functional performance of components and processes. In contrast to a disturbance, evolutionary changes are persistent rather than transient. An example of an internal evolutionary force is the gradual deterioration of infrastructure through an aging process. An example of an external evolutionary force that may affect the functional performance of navigation infrastructure is sea-level rise. An evolutionary force may induce a trend in the functional performance of a system. A gradual loss in functional performance that occurs in response to an evolutionary force can be offset through some form of adaptation. For example, gradual increases in shoaling rates in a navigation channel might be offset by an increase in frequency or intensity of dredging activity.

Many different types of natural and anthropogenic disturbances can potentially affect the performance of an ICS. Coastal storms are a common and ubiquitous form of disturbance that may affect USACE missions in a variety of different ways. For example, coastal storms can lead to shoaling in navigation channels, limiting access to ports. Coastal storms can lead to the erosion of coastlines, reducing the level of protection against storm events. Coastal storms can alter the condition of restored habitats and affect the integrity of ecological communities. Therefore, coastal storms provide a useful focal point for discussing resilience in the context of an ICS. While the remainder of this report discusses disturbances in the form of coastal storms, the methods and ideas presented in this report could easily be extended to consider many different types of disturbances (e.g., earthquakes, oil spills, etc.).

\section{Resilience to disturbance}

Resilience to a disturbance and the effect of an evolutionary force on resilience to a disturbance are illustrated in Figure 2. Prior to the disturbance, the system is operating at a pre-disturbance level of performance, $Q$. In Figure 2(a), a disturbance occurs at time $t_{o}$, causing a performance impairment of $d$. This is followed by a recovery period during which system performance is restored to a pre-disturbance performance level at time $t$. The length of time needed to recover the pre-disturbance 
performance level is called rapidity: $r=t-t_{0}$. An evolutionary force occurs on a time scale that exceeds the time scale on which a disturbance occurs and may exceed the planning horizon considered in designing the system. Figure 2(b) shows that, for a disturbance of some magnitude, the effect of an evolutionary force over time is to alter the level of performance impairment and the duration of the recovery period. As discussed previously, it is assumed that $\Delta t$ is much greater than $r$.

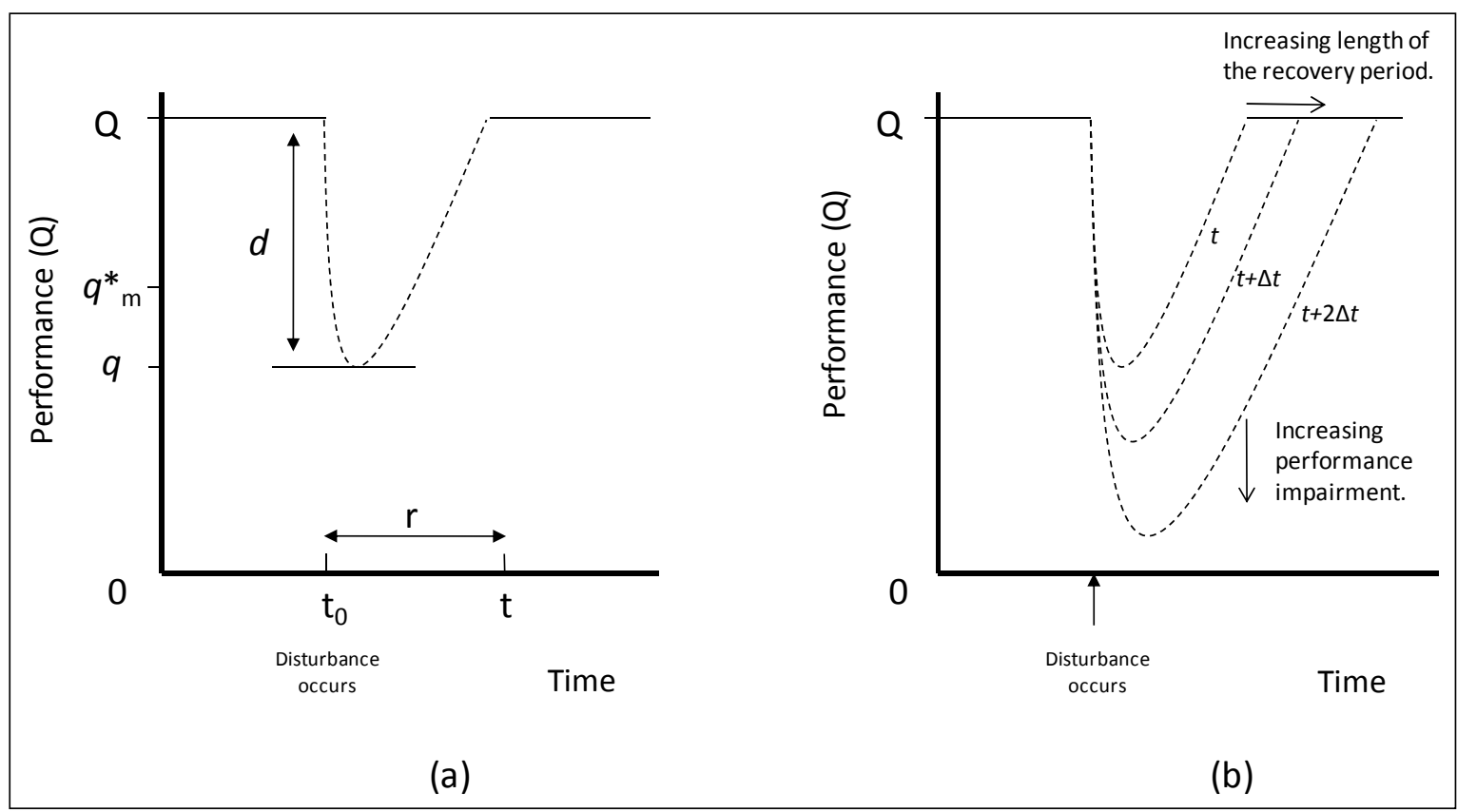

Figure 2. Resilience to a disturbance and the effect of an evolutionary force. Panel (a) shows the functional response and recovery of a system following a disturbance of magnitude $m$. Panel (b) shows the potential effect of an evolutionary force on system response and recovery from a disturbance of magnitude $m$. Panel $b$ shows that, for $\Delta t$ much greater than $r$, an evolutionary force can potentially increase the duration and level of performance impairment caused by a disturbance of a given magnitude.

\section{A general method to quantify resilience}

Engineering resilience is the propensity of a system to resist functional impairments as a result of a disturbance and to recover a pre-disturbance level of performance following a disturbance. This section of the report proposes a general method to quantify resilience in ICSs. The overall approach builds on the work of Bruneau et al. (2003), Chang and Shinozuka (2004), and Bruneau and Reinhorn (2007), who have studied the resilience of infrastructure systems to earthquakes, and on the work of Reed et al. (2009), who have studied the resilience of networked infrastructure to hurricanes. 
Engineering resilience is described in Figure 3, which illustrates the loss and recovery of system performance following a disturbance that occurs at $t_{0}$. The vertical axis is system performance, $Q$. Functional performance can be measured in terms of any useful metric or combination of metrics. Performance is usually normalized to a scale from 0 to 1 , with $Q_{\infty}=1$ representing a nominal pre-disturbance performance level and $Q=0$ representing complete non-performance (Chang and Shinozuka 2004, Reed et al. 2009). This effectively bounds $d$ between 0 and 1 . If a disturbance causes system performance to drop to $q$, this results in a performance impairment of $d=Q_{\infty}-q$. In Figure 2, the performance impairment actually realized is less than the performance objective, $d^{*}$ m, considering the magnitude of the disturbance that occurred. The sojourn period, $r_{\mathrm{S}}$, is the time between the occurrence of the event and the attainment of critical performance level, $q^{*} \mathrm{~m}$ (Hashimoto et al. 1982a). The rapidity of recovery $r$ is the time between the disturbance event $t_{0}$ and the time at which a pre-disturbance level of performance is recovered $t$. In this figure, the recovery period is shorter than the recovery objective for a disturbance of magnitude $m, r^{*}$.

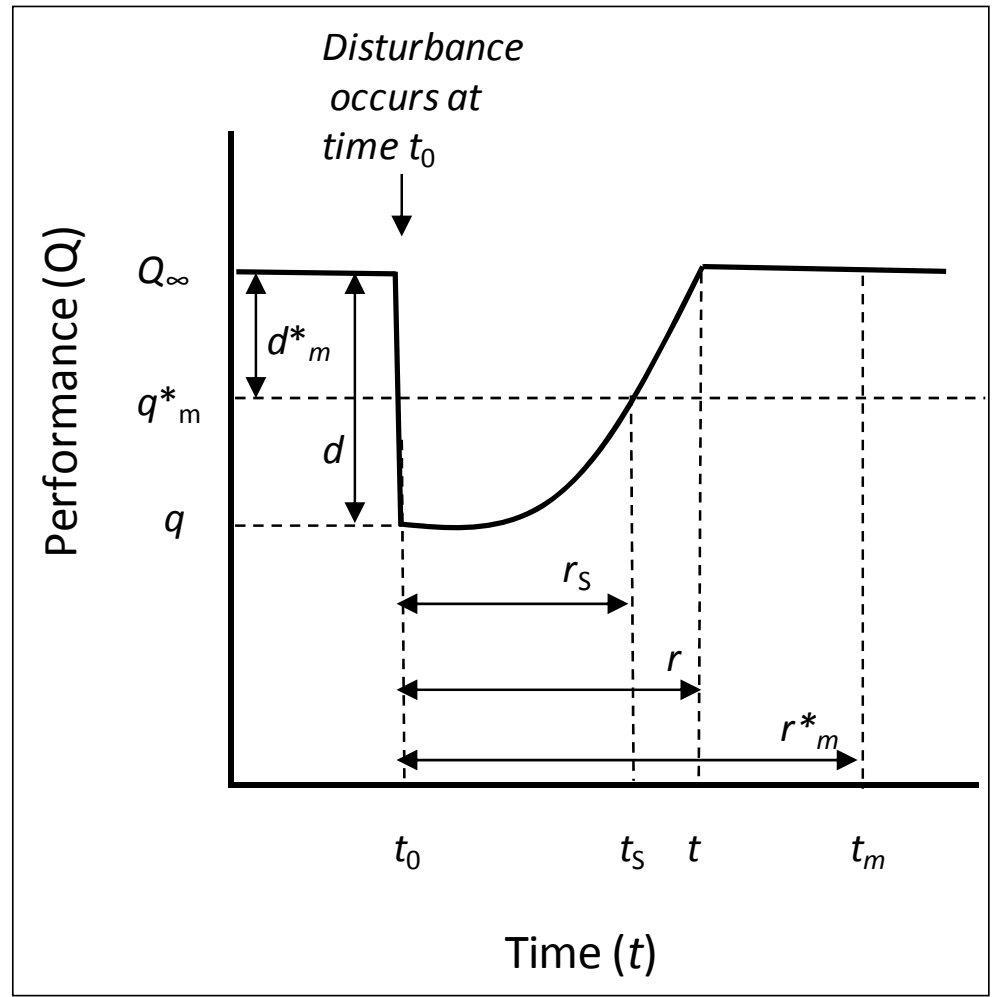

Figure 3. Resilience and performance objectives. The response and recovery of system performance $(Q)$ to a disturbance of magnitude $m$ is illustrated over time, incorporating management objectives for system response and recovery (after Bruneau et al. (2003), Chang and Shinozuka (2004)). 
Chang and Shinozuka (2004) define a probabilistic measure of engineering resilience as the probability of satisfactory performance and recovery $A$, given the severity (magnitude) of an event $m$ :

$$
p(A \mid m)=p\left(d \leq d^{*}{ }_{m} \cup r \leq r{ }_{m}^{*}\right)
$$

A system performs satisfactorily in the face of a disturbance of magnitude $m$ if the performance impairment $d$ caused by the disturbance is less than a critical level of performance impairment $d^{*}$, and the length of time required to recover the pre-disturbance performance level $r$, that is less than a critical duration of performance impairment $r^{*} \mathrm{~m}$. The subscript $m$ represents the severity of the disturbance, but could also represent a set of explicit boundary conditions that determine event severity. For example, the severity of a hurricane can be described by a Saffir-Simpson scale index, but could also be described by a vector of storm parameters representing a set of external forces acting on the coastal system such as radius to maximum winds, barometric pressure, forward speed, direction, etc. The variables $d^{*}{ }_{\mathrm{m}}$ and $r_{\mathrm{m}}{ }_{\mathrm{m}}$ are management objectives that are established prior to the event. The incorporation of management objectives into the measure of resilience is an important feature because it establishes a criterion for satisfactory performance and recovery. This concept is illustrated in Figure 4. A system that is resilient to a disturbance of magnitude $m$ is one that exhibits acceptable performance in terms of the performance limit state and the rapidity limit state.

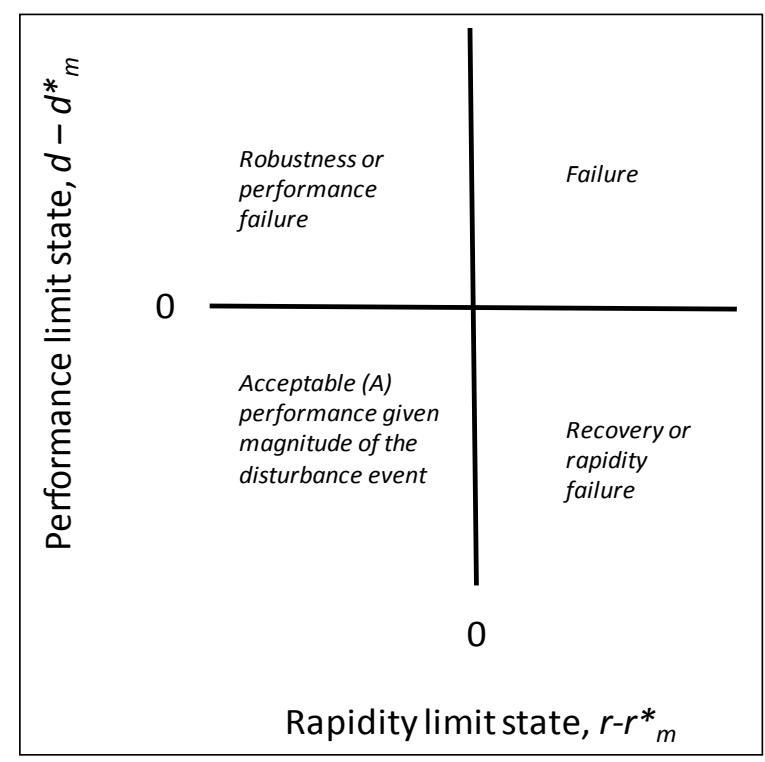

Figure 4. Regions of success and failure in the performance and recovery space (after Chang and Shinozuka (2004)). 


\section{Reliability theory}

The probabilistic approach to engineering resilience is rooted in the theory of reliability analysis. This section of the report provides a brief introduction to the topic to help facilitate the discussion of resilience. However, the literature on reliability analysis is extensive and the theories are very well developed (e.g., Melchers 1999, Moddarres et al. 2010). Reliability is the probability that a system will perform its intended function when it is subjected to a stress. The safety margin is the difference between a system's capacity to resist being forced into a failure state $C$, and the demands of stress placed on that system $D$ :

$$
Z=C-D
$$

This equation is known as the limit state equation. ${ }^{1}$ Capacity is the ability of a system to resist failure under specific conditions, demand is the load placed on the system, and $Z$ is the limit state or safety margin. If $Z \geq 0$, the system resists failure and if $Z<0$, the system fails. The connection to the limit state conditions for performance and rapidity should be obvious. The capacity corresponds to the allowable performance impairment or recovery period and the demand corresponds to the performance and recovery periods that are realized.

In probabilistic reliability theory, $C$ and $D$ are treated as random variables to characterize uncertainty in capacity and demand and $Z$ is a random variable. Capacity and demand can further be defined as a function of some vector of basic random variables $\mathbf{X}$, representing structural design parameters (e.g., material properties, geometry, or dimensions) and environmental variables or boundary conditions that might in some way affect system reliability. The limit state equation can then be written as the difference between two random variables representing the capacity of the system to resist a load, $G_{C}(\mathbf{X})$, and the load placed on that system $G_{D}(\mathbf{X})$ :

$$
Z=G(C, D)=G(\mathbf{X})=G_{C}(\mathbf{X})-G_{D}(\mathbf{X})
$$

The solution space consists of three regions: $G(C, D)<0$ is a failure state; $G(C, D)=0$ is the limiting state; and $G(C, D)>0$ is the survival state. Basic

1 The limit state equation is more commonly written as a function of resistance $R$ and stress $S$ : $Z=R-S$. However, this report avoids this notation to prevent confusion with other uses of the symbol $R$. 
variables can be either random variables or deterministic variables. If $\mathbf{X}$ is a vector of basic random variables, the probability of failure is given by integration of a multivariate density function for the $n$-dimensional vector of basic random variables over the failure domain, $G(\mathbf{X}) \leq 0$ (Melchers 1999):

$$
p[G(X) \leq 0]=\int \ldots \int_{G(\mathrm{x}) \leq 0} f_{\mathrm{X}}(\mathrm{x}) d \mathrm{x}
$$

If some of the basic variables are deterministic, $p[G(\mathbf{X}) \leq 0]$ is conditioned on the value of these variables. If all basic variables are deterministic, there is no uncertainty in the safety margin.

A fragility curve is a function that gives the probability that the component or process will fail to perform its function under the range of demands to which it may be subjected. A fragility curve is constructed by calculating the probability of failure, $p[G(\mathbf{X}) \leq 0]$, under demands ranging from those at which failure is highly unlikely to those at which failure is almost certain. There are numerous approaches to developing fragility curves including judgmental, empirical, and analytical methods (Schultz et al. 2010). Judgmental methods are based on expert knowledge or engineering judgment. Empirical methods are based on data from historical records of failures. Analytical methods are based on structural models that characterize the performance limit state of the component, process, or system. The models used in analyzing reliability can range from simple to complex, and simplified representations of more complex models are often used as substitutes for numerical models. It should be noted that an analysis of the uncertain capacity of a complex system to maintain its functional performance in the face of a disturbance can be a difficult task.

\section{Robustness of subsystem components and processes}

The ICS consists of three basic subsystems including the navigation, storm damage reduction, and ecosystem restoration subsystems. Each of these subsystems is supported by a set of components and processes that have specific functions that support the overall function of the subsystem. Ultimately, the performance of the subsystems and the ICS as a whole will depend upon the functional performance of these various components. Failure of these system components in different combinations and to different degrees will lead to varying levels of overall system performance. 
For any component or process $i$, the performance impairment $D_{i}$ is the difference between a nominal pre-disturbance performance level $Q_{i, \infty}$ and the performance level following the disturbance, $Q_{i}$ :

$$
D_{i}=Q_{i, \infty}-Q_{i}
$$

The level of performance following a disturbance will be uncertain; therefore, $Q_{i}$ is a random variable with uncertainty in the level of performance actually realized, $q_{i}$, described by a probability density function, $f_{Q_{i}}\left(q_{i} \mid m\right)$.

Uncertainty about functional performance arises from lack of knowledge about how the performance of subsystem components and processes will respond to loads placed on the system. The difference, $D_{i}$, is a random variable that represents the demand placed on the system. While it is conceivable that nominal performance could also be treated as a random variable, this report treats it deterministically. Uncertainty in nominal performance might arise from natural variability in environmental boundary conditions.

The component or process $i$ resists a disturbance if functional performance remains above a pre-determined performance threshold, $q^{*}{ }_{i, m}$ (see Figure 2). If the component or process resists a disturbance, it is said to be robust against that disturbance. The critical performance margin, $d^{*}{ }_{i, m}$, is:

$$
d^{*}{ }_{i, m}=Q_{i, \infty}-q^{*}{ }_{i, m}
$$

The performance threshold and the critical performance margin are management objectives; therefore, they are deterministic values. The success or failure of a system to function at the desired level is assessed using a limit state equation. The limit state for functional performance is the difference between the deterministic critical performance margin, representing the capacity of a component or process, and the uncertain actual performance impairment, representing the demand placed on that component or process:

$$
Z_{i}=G_{i}(\mathrm{X})=d_{i, m}^{*}-D_{i}(\mathrm{X})
$$

$Z_{i}$ is the performance margin, which is analogous to the safety margin in reliability theory. The limit state equation for a component or process $i$, can also be expressed as the difference between the capacity of the system to 
resist a load, $d^{*}{ }_{i, m}$, and the load placed on that system, $D_{i}(\mathbf{X})$, where $\mathbf{X}$ is a vector of basic variables representing uncertain material properties and environmental boundary conditions related to the disturbance of interest. In this representation, it is assumed that every possible realization of $\mathbf{X}$ can be associated with a particular event magnitude $(\mathbf{x} \in m)$.

The component or process successfully resists the disturbance if $z_{i} \geq 0$ and the system fails to resist a disturbance if $z_{i}<0$. The probability that the system resists a disturbance of magnitude $m$ is:

$$
p\left(z_{i} \geq 0 \mid m\right)=\int_{-\infty}^{0} f_{Z_{i}}\left(z_{i} \mid m\right) d z_{i}
$$

Reliability $\rho$ is defined as the complement of the probability of failure:

$$
\rho=1-p\left(z_{i}<0 \mid m\right)
$$

An assessment of component or process reliability requires the analyst to specify what constitutes failure. Critical failure conditions for a component or process of an ICS will reflect the contribution of that component or process to the overall functionality of the system. This may require specification of multiple failure conditions. For example, navigation channels function to provide cargo ships with access to commercial ports. Sediment loads caused by coastal storms could limit the passage of ships in and out of the port. A fragility curve for a navigation channel would estimate the probability that sedimentation within the channel blocked ships requiring a particular draft. In this case, the analyst must specify a critical draft. As shown in Figure 4, different critical drafts will lead to different fragility curves, with fragility curves for ships with deeper drafts indicating higher probabilities of failure than fragility curves for shallow draft ships.

The failure of coastal processes can be considered as well as the failure of components. For example, the stability of a shoreline may depend upon the existence of a natural sand supply that balances the loss of sand caused by erosion. Changes in the supply of sand or the rate of erosion brought about by changes in boundary conditions affecting that system could lead to a change in the location of the shoreline. In this example, the resistance of the process could be represented by the volume of sand supplied per unit time and the load could be represented by the volume of sand eroded per unit time. A failure condition for this process should also take into 
account the length of process interruption. For example, an interruption on the scale of hours or days may have little meaning for the long-term functionality of the ICS - and therefore may have little significance for an analysis of resilience. However, a permanent change in the volume of sand supplied per unit time or the rate of erosion may be significant.

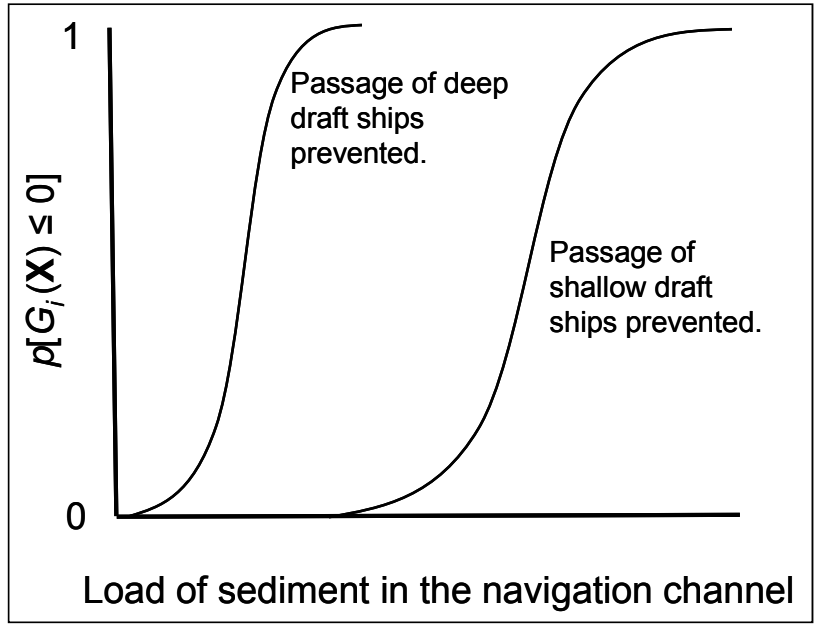

Figure 5. Fragility curves for component and process function. Hypothetical fragility curves for a navigation channel showing how different criteria for functionality of the channel lead to different probabilities of failure.

\section{Functional dependence among subsystem components and processes}

The components and processes in an ICS that work in concert, enabling the system to perform its overall function, form an inter-dependent network of infrastructure. In an inter-dependent network, the failure of one component or process may affect the probability of failure of other components or processes. Reed et al. (2009) describe a method of analyzing the interoperability of infrastructure networks derived from Haimes (2004) inputoutput model approach. The approach involves constructing an $n \times n$ interoperability matrix, $\mathbf{B}$, containing the probability of failure for component or process $i$ conditional on the failure of every other component or process in the network. For $i=\{1,2, \ldots, j, \ldots, n\}$ components and processes:

$$
\mathbf{B}=\left[b_{i j}\right]_{n \times n}
$$

The elements of this matrix along the diagonal $b_{i, j=i}$ are equal to o. The elements off the diagonal are conditional failure probabilities for each pair of components or processes: 


$$
b_{i, j \neq i}=p\left[z_{i} \leq 0 \mid z_{j} \leq 0\right]
$$

The failure probabilities for each subsystem are then adjusted to account for inter-dependence with other subsystems, where subsystems are analogous to components and processes. This involves solving a set of linear equations simultaneously:

$$
\mathrm{z}=\mathrm{Bz}+p\left(z_{i} \leq 0 \mid m\right)
$$

Here, $\mathbf{z}$ is a vector of updated (modified) probabilities for component or process inoperability given $m$. B is the inter-operability matrix, and $z_{i}$ is the performance margin for the component or process given $m$. Reed et al. (2009) demonstrate how $b_{i j}$ can be estimated from historic data on the operability of networked subsystems following disaster events.

Equation 8 suggests that the level of performance impairment can be defined in terms of a probability of component or process failure. This was the method adopted by Reed et al. (2009) in analyzing electrical and telecommunications service outages. In that study, the level of impairment and the probability of subsystem failure were each defined as the fraction of the population within a county without utility service. One could argue that, in that case, this is a reasonable approach. However, one might imagine systems for this approach would need to be modified. This report does not propose a solution for such a case.

A difficult feature of interoperability matrices is the need to obtain data on or otherwise specify the reliability of each networked component given the state of every other component or process, even in the absence of a functional relationship between those components or processes. Bayesian network models (Pearl 1988) may provide an alternative approach to modeling the interoperability of such systems. The approach requires that conditional probabilities between two components or processes be calculated when there is a cause-and-effect relationship between them, but not when a cause-and-effect relationship does not exist between two components or processes. 


\section{Rapidity of system components and processes}

Prior to the occurrence of an event, the rapidity (e.g., time to recovery) of functional performance will be uncertain and will depend upon the level of performance impairment actually realized. Since actual performance cannot be known prior to the event, recovery objectives should reflect an anticipated performance level given the magnitude of the disturbance $m$. The probability of meeting recovery objectives can be defined as:

$$
p\left(r-r^{*}{ }_{m} \leq 0 \mid m\right)=\int_{0}^{r^{*}} f_{R}(r \mid m) d r
$$

Here, the difference between rapidity and the rapidity objective is the limit state condition and $f_{R}(r \mid m)$ is a probability density function that describes uncertainty in the duration of the recovery period. Uncertainty can be evaluated using expert judgment based on experience dealing with past disturbance events of similar magnitude or can be based on records of past recovery efforts.

\section{Performance function for components and processes}

Each component or process has a specific function that supports the overall function of the navigation, storm damage reduction, or ecosystem restoration subsystem. The performance of that function over time can be described as a function of uncertain variables that characterize uncertainty in robustness and rapidity. For example, Bruneau et al. (2003) proposed that performance could be modeled as a function of time using the equation:

$$
Q_{i}(t)=Q_{i, \infty}-D_{i}(\mathbf{X}) \exp \left(-\beta_{i} t\right)
$$

where $Q_{i, \infty}$ is the nominal performance level for component or process $i$ prior to the disturbance event (normalized to one). $D_{i}(\mathbf{X})$ is a random variable representing the level of performance impairment as a function of boundary conditions during the modeled event, and $\beta_{i}$ is a rapidity parameter that describes the speed of recovery following the disturbance. Reed et al. (2009) have shown how $\beta$ can be estimated empirically from historical data on post-event disaster recovery and have demonstrated that this form of the performance function appears suitable for electrical and telecommunications infrastructure. 
The functional form of the performance function in Equation 14 may not be appropriate for many components and processes in coastal systems because it imposes a diminishing marginal rate of recovery on the performance trajectory. The pattern of recovery may be quite different in ICSs than is suggested here. For example, the need to plan and mobilize construction efforts to repair infrastructure may impose delays in recovery for several years, followed by rapid recovery as construction projects are completed. Therefore, other forms for the performance function should be considered. Having acknowledged this fact, this function is used here for the purpose of discussion.

\section{Resilience of subsystem components and processes}

Resilience of a component or process to a disturbance event of magnitude $m$ is the joint probability of meeting both a resistance and recovery objective for the component or process function given the magnitude of the event:

$$
p\left(A_{i} \mid m\right)=\int_{0}^{z^{*}{ }^{*} r^{*}{ }^{*}} \int_{0} f_{Z_{i} R_{i}}\left(z_{i}, r_{i} \mid m\right) d z_{i} d r_{i}
$$

Here, $p\left(A_{i} \mid m\right)$ is the probability of maintaining an acceptable level of functional performance and/or recovering pre-disturbance performance levels within an acceptable time period given the magnitude of an event. An overall measure of resilience for component or process $i, \gamma_{i}$ can be computed by simulating component or process functional performance over the full range of potential disturbance events, as suggested by Chang and Shinozuka (2004):

$$
\gamma_{i}=\sum_{m} p\left(A_{i} \mid m\right) p(m)
$$

A Monte Carlo simulation of the performance function for a component or process can be used to derive the joint probability distribution for each component or process. Outcome performance metrics with which to evaluate functional performance as well as the form of the performance function will likely differ widely among different components and processes. In Equation 14, above, $\beta$ can be estimated for each component or process from historical performance and recovery data or expert knowledge (engineering judgment). The uncertain parameter would then be treated as 
a random variable and the uncertain performance trajectory can be forecasted with confidence intervals using a Monte Carlo simulation approach or possibly even using an analytical approach. Results of the forecast are then used to estimate resilience for each component or process.

\section{Resilience of individual subsystems and the ICS}

Resilience of the ICS $\gamma$ can be expressed as some function of the $n$ resilience measures for components or processes:

$$
\gamma=h\left(\gamma_{1}, \gamma_{2}, \ldots \gamma_{i} \ldots \gamma_{n}\right)
$$

This approach was suggested by Reed et al. (2009), but these authors provide no suggestions as to the form this function should take. One possibility would be to use a multi-attribute value function (Keeney and Raiffa 1993). This approach involves calculating an overall measure of resilience for the ICS using a weighted sum of resilience measures for each component or process to estimate resilience of the subsystem:

$$
\gamma=\sum_{i=1}^{n} w_{i} \gamma_{i}
$$

Weights, $w_{i}$, on the resilience of each component and process reflect the relative importance of that component and process function to the overall performance of a subsystem. This may require coastal managers to make value judgments with respect to relative importance. It should be noted that the additive function in Equation 18 assumes preferential independence with respect to component and process function (Keeney and Raiffa 1993). This means that coastal managers' willingness to make trade-offs between two component or process functions must be independent of the performance levels for those functions. Over time, these weights could be adjusted to reflect changes in coastal management priorities.

To obtain a measure of resilience for the ICS as a whole, an approach similar to that described in Equations 17 and 18 could be used to aggregate the resilience measures for navigation, storm damage reduction, and ecosystem restoration subsystems. In this case, subsystems that serve functions that are regarded as being more important in a particular ICS are assigned higher weights. The caveats that apply to aggregation of resilience 
measures for components and processes also apply to the aggregation of subsystem resilience measures.

The approach to quantifying resilience described in this report requires a decomposition of ICS components and processes and an estimation of resilience measures for each component and process. Resilience measures are aggregated to obtain a measure of resilience for each subsystem, and subsystem resilience measures are aggregated to obtain a measure of resilience for the ICS. In theory, it would be possible to estimate resilience for the subsystem directly by identifying a single function for that subsystem, modeling the effect of changes in boundary conditions on that function, and evaluating resilience for the subsystem directly. It would also be possible to define multiple functions for each subsystem, analyze the resilience of these functions, and then aggregate the individual resilience measures into an overall measure of the subsystem as shown in Equation 17. However, the difficulty with this approach is that this would require a model describing how the functional performance of a subsystem responds to changes in boundary conditions. To the extent that the performance measures for components are processes that may be more well-defined and narrower in scope, it seems more feasible to model the resilience of individual components and processes than overall system performance.

\section{Evolution of resilience}

The term evolution of resilience refers to a trend in the probability of meeting robustness and recovery objectives. The gradual change in resilience over time is caused by an evolutionary force that affects the robustness of system components and processes and/or the rapidity with which pre-disturbance performance levels can be restored. The evolutionary force is a gradual and persistent change in boundary conditions that occurs over a time scale that is much longer than the time scale on which the disturbance of interest occurs. For example, coastal storms occur on an hourly or daily time scale. Sea-level rise occurs over a period of decades and centuries. Thus, changes in sea level may induce a trend in the resilience to coastal storms over decades and centuries.

An evolutionary force may induce a trend in either resilience or functional performance, or both. Because resilience is assessed relative to predisturbance performance levels, it is important to separate these two effects. The management response to an evolutionary force is some form of adaptation to maintain the desired level of resilience or the desired level of 
functional performance. The effect of an evolutionary force on resilience is illustrated in Figure 6, which shows decreases in robustness and rapidity in response to changes in an external or boundary condition. In this figure, the quality of performance is not affected by the evolutionary force, but could be. Not all trends in resilience are the result of changes in external forces. Changes in the conditions within a system may also enhance or diminish resilience over time (Bruneau and Reinhorn 2004, O’Rourke 2007). For example, improvements in communication and coordination among first responders may tend to increase the probability of performance recovery within a desired recovery time. Similarly, changes in the capacity to respond to disturbances (resourcefulness) may induce a trend in resilience. Programs for periodic investment to maintain and improve coastal infrastructure may also induce a positive trend in resilience.

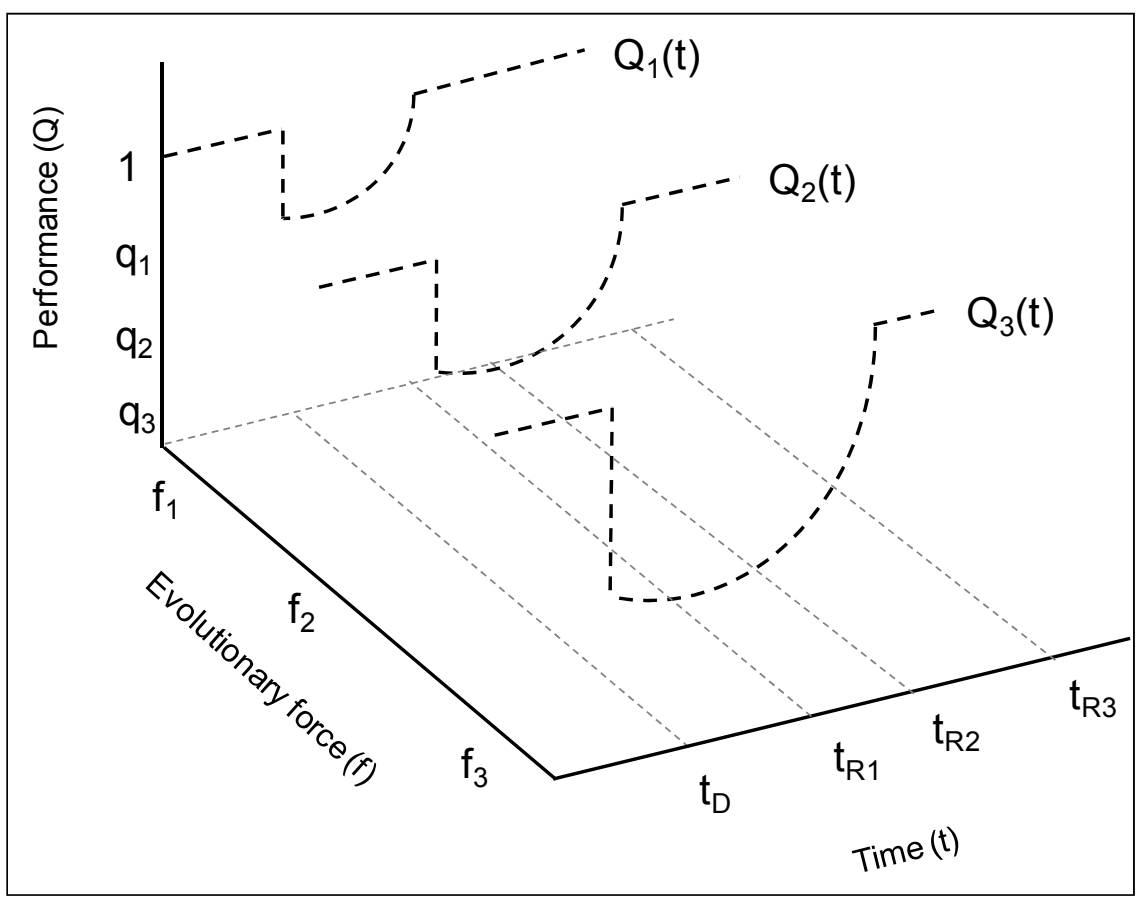

Figure 6. System resilience changes in response to an evolutionary force (after O'Rourke (2007)). The figure shows that as boundary conditions change from $\mathrm{f} 1$ to $\mathrm{f} 3$, the robustness of the system diminishes and the rapidity with which it recovers also diminishes. An opposite effect might also be possible. The evolutionary force dimension might also represent changes in resourcefulness or redundancy or other system characteristics, such as the effectiveness of communication among emergency responders, as in O'Rourke (2007). 


\section{A step-by-step procedure for evaluating resilience in ICSs}

The following steps outline a procedure for analyzing the engineering resilience of ICSs as described above. This analysis of resilience requires a simulation of the performance of components and processes that comprise a subsystem subject to the variability of boundary conditions. While simpler, more expedient approaches to evaluating resilience may be available, it is beyond the scope of this report to describe them. Generally, it is expected that those methods will be found as more experience is gained performing these types of analysis.

\section{Identify one or more functional performance objectives for} each ICS subsystem. For example: Navigation subsystem performance might be expressed in terms of limiting depth or shipping cost per ton. Storm damage reduction subsystem performance could be expressed in terms of the risk reduction benefits of the storm damage infrastructure. Ecosystem restoration project performance might be expressed in terms of the ecological output measures (e.g., acres of wetland, biomass in restored oyster beds, number of nesting pairs of birds, etc.).

2. Decompose each subsystem by identifying the components and processes that support each functional performance objective. Consider the function(s) of each component or process with respect to subsystem function. A component or process should be selected for analysis if its failure to maintain function would affect functional performance of the subsystem. To keep the problem tractable, every attempt should be made to limit the number of components and processes selected for analysis. Components and processes are indexed $i=\{1,2,3, \ldots, j, \ldots n\}$. Examples of ICS components and processes and their functions are outlined in Tables 3-5. This list is generic and may be adapted as necessary.

\section{Establish performance measures for the function of each} component and process. For example: If a navigation channel is identified as a component of the navigation subsystem, its performance might be expressed in terms of its limiting depth. If a breakwater is identified as a component of the storm damage reduction subsystem, its performance could be expressed in terms of its risk reduction benefit. If a sand bypassing plant is an important feature for preventing erosion of a shoreline that provides protection from storm damage, its performance might be evaluated in terms of the net transfer of sand to the deposition site. The performance of components and processes associated with ecosystem restoration projects might be expressed in terms of ecological 
output measures such as wetland acreage maintained, biomass in restored oyster beds, or number of nesting pairs of birds.

4. Establish performance objectives for each component and process function in terms of selected performance metrics considering each possible level of event severity: $q_{\mathrm{m}}^{*}$. In establishing performance objectives, one should account for the risk associated with component or process failure (i.e., potential performance losses given a disturbance of severity $m$ and the probability that a disturbance of severity $m$ could occur. For example, more stringent performance objectives may be justified when the potential cost of a performance loss is high or the probability that a disturbance that would induce a loss is high. There is an economic tradeoff between the cost of designing and managing systems to remain functional in the face of a disturbance and the cost of expected performance loss. The lower the probability of a disturbance and the lower the potential cost of functional performance impairments, the more difficult it is to make an economic argument to manage for robustness and rapidity, should that disturbance event occur.

\section{Develop a fragility curve for each component and process} function: $G_{i}(\mathbf{X})$. The fragility curve describes the conditional probability of failing to meet subsystem performance objectives given the set of internal and external (environmental) forces $(\mathbf{X})$ acting on the system. The fragility curve simultaneously characterizes uncertainty in what magnitude of disturbance would cause the component or process to fail, which is defined as performing at a level below the objective level of functional performance.

6. Transform the fragility curve to characterize uncertainty in functional performance given the level of environmental force acting on the component or process: $D_{i}(\mathbf{X})$. This can be done because fragility is a function of the environmental force.

7. Develop an inter-operability matrix, $B$, and update the probabilities of functional performance.

8. Establish recovery objectives for each component or process: $r^{*}$. Recovery objectives describe how quickly pre-disturbance levels of performance should be restored after a disturbance event of particular magnitude has occurred. The caveats for establishing performance objectives (Step 3) also apply to establishing recovery objectives. 
9. For each component or process, characterize uncertainty in the time that would be required to restore the pre-disturbance performance level of that component or process given the severity of the disturbance event: $f_{R}(r \mid m)$. Uncertainty is characterized using a probability density function.

10. Using a suitable performance function, $\left.Q_{i}(t)\right)$, simulate performance for each level of event severity, $\mathbf{m}$, accounting for uncertainty in the response and rapidity of the component or process function.

11. Calculate $p(A \mid m)$ for each component or process from the performance trajectory for that component or process using Monte Carlo simulation. Sources of uncertainty in this simulation are the level of performance impairment and the rapidity.

12. Calculate a measure of resilience for the subsystem as a whole and aggregate subsystem resilience measures to obtain a measure of resilience for the ICS. This is accomplished by aggregating the measures of resilience for components and processes as suggested in Equation 17. 


\section{Integrated Coastal Systems}

An ICS is an open, engineered system that functions to provide safe, reliable, and efficient access to ports and harbors, reduces the risk of economic loss from flooding in coastal communities, and sustains healthy and diverse biotic communities by providing appropriate habitat. The components and processes of an ICS will of course vary from site to site. This section of the report considers how an ICS may be decomposed into a set of components and processes for an analysis of ICS resilience. Components and processes of an ICS are described in Tables 3-5, as are their functions with respect to the three primary USACE missions. By describing the ICS components and processes, the authors hope to suggest what kinds of issues might need to be addressed in an analysis of resilience and suggest ways of structuring an analysis of resilience using the quantitative approaches described in Chapter 2.

\section{Navigation subsystem}

In general, the overall function of a navigation subsystem is to provide sufficient limiting depth and air draft to enable ships to access a port where cargo can be loaded and offloaded at a cost that is competitive. Suitable performance measures for the navigation subsystem of an ICS might include the limiting depth and air draft of the navigation channel or the cost per ton of cargo shipped into and out of the port. Since the analysis is quantitative, it will be helpful to be as precise and unambiguous as possible about the meaning of the term navigation, perhaps by specifying a vessel class (vessels with a common length or style of hull, width of beam, or superstructure) for which access is to be provided. Thus, an analysis of resilience might respond to the question "How resilient is the navigation function with respect to permitting access for vessels of class X?" In this case, it is possible that a navigation subsystem could be associated with multiple functions, one for the navigation of each possible class of ships. This leads to multiple analyses of resilience in a navigation subsystem. For practical reasons, to keep the analysis tractable, these analyses might be restricted to only the most important class of vessels operating in that system. 
Table 3. Components and processes that comprise the navigation subsystem.

\begin{tabular}{|c|c|c|}
\hline Component & Description & Function \\
\hline Jetties & $\begin{array}{l}\text { Rubble-mound structures at a river } \\
\text { mouth or tidal inlet perpendicular to } \\
\text { coastline. }\end{array}$ & $\begin{array}{l}\text { Stabilize navigation channel entrance and } \\
\text { prevent longshore sediment from entering the } \\
\text { inlet. }\end{array}$ \\
\hline $\begin{array}{l}\text { Navigation } \\
\text { channels }\end{array}$ & $\begin{array}{l}\text { Natural and artificial waterways that } \\
\text { connect the open ocean with ports and } \\
\text { harbors. }\end{array}$ & $\begin{array}{l}\text { Provide sufficient limiting depth to allow ships of } \\
\text { a designated draft to access a port or harbor. }\end{array}$ \\
\hline $\begin{array}{l}\text { Port } \\
\text { infrastructure }\end{array}$ & $\begin{array}{l}\text { Piers, wharves, cranes, and staging } \\
\text { areas. }\end{array}$ & $\begin{array}{l}\text { Provide for loading and offloading of civilian and } \\
\text { military ships. }\end{array}$ \\
\hline Turning basins & $\begin{array}{l}\text { Areas of navigable depth that are } \\
\text { outside berthing areas and navigation } \\
\text { channels. }\end{array}$ & $\begin{array}{l}\text { Provide areas of sufficient limiting depth where } \\
\text { ships of a designated draft can turn and } \\
\text { maneuver. }\end{array}$ \\
\hline Bridges & $\begin{array}{l}\text { Concrete or steel structures that are } \\
\text { designed to permit vehicle traffic to } \\
\text { cross the navigation channel. }\end{array}$ & $\begin{array}{l}\text { Provide ships with sufficient air clearance to } \\
\text { pass underneath. }\end{array}$ \\
\hline $\begin{array}{l}\text { Offshore disposal } \\
\text { sites }\end{array}$ & $\begin{array}{l}\text { Offshore areas designated for the } \\
\text { placement of uncontaminated dredged } \\
\text { material that is not required for } \\
\text { beneficial use. }\end{array}$ & $\begin{array}{l}\text { Provide an off-shore location for the disposal of } \\
\text { uncontaminated dredged material removed from } \\
\text { navigation channels. }\end{array}$ \\
\hline $\begin{array}{l}\text { Beneficial use } \\
\text { placement areas }\end{array}$ & $\begin{array}{l}\text { Areas where dredged material from } \\
\text { navigation channels can be placed for } \\
\text { a beneficial use. }\end{array}$ & $\begin{array}{l}\text { Provide a location for uncontaminated dredged } \\
\text { material removed from navigation channels. }\end{array}$ \\
\hline $\begin{array}{l}\text { Confined } \\
\text { disposal facilities } \\
\text { (CDFs) }\end{array}$ & $\begin{array}{l}\text { Diked containment areas that have } \\
\text { been engineered to hold contaminated } \\
\text { dredged material. }\end{array}$ & $\begin{array}{l}\text { Provide a place to deposit contaminated } \\
\text { dredged material removed from navigation } \\
\text { channels. }\end{array}$ \\
\hline Locks & $\begin{array}{l}\text { Structures designed to permit } \\
\text { navigation in areas where the elevation } \\
\text { gradient is otherwise too steep. }\end{array}$ & $\begin{array}{l}\text { Provide access to upstream navigation channels } \\
\text { that would otherwise be inaccessible. }\end{array}$ \\
\hline Navigation gates & $\begin{array}{l}\text { Openings in tide barriers that may be } \\
\text { closed during periods of unusually high } \\
\text { tide. }\end{array}$ & $\begin{array}{l}\text { Provide ships with access to protected areas } \\
\text { along the coast during periods of normal tide. }\end{array}$ \\
\hline $\begin{array}{l}\text { Near-shore } \\
\text { berms }\end{array}$ & $\begin{array}{l}\text { Uncontaminated dredged material from } \\
\text { navigation channels deposited in the } \\
\text { surf zone. }\end{array}$ & $\begin{array}{l}\text { Provide a repository for dredged material and a } \\
\text { source of sand for nourishing down-coast } \\
\text { beaches. }\end{array}$ \\
\hline Breakwaters & $\begin{array}{l}\text { Rubble-mound structures at the } \\
\text { entrance to harbors. }\end{array}$ & $\begin{array}{l}\text { Protect ships and port infrastructure from wave } \\
\text { action and storms. }\end{array}$ \\
\hline $\begin{array}{l}\text { Dredged material } \\
\text { disposal }\end{array}$ & $\begin{array}{l}\text { The placement of dredged material } \\
\text { away from inlets in such a manner that } \\
\text { it will not return to the dredged } \\
\text { channel. }\end{array}$ & $\begin{array}{l}\text { Relocate dredged material away from navigation } \\
\text { channels. }\end{array}$ \\
\hline Dredging & $\begin{array}{l}\text { The periodic removal of sediments } \\
\text { from navigation channels, turning } \\
\text { basins, and berthing areas. }\end{array}$ & $\begin{array}{l}\text { Restore or increase the limiting depth in a } \\
\text { navigation channel. }\end{array}$ \\
\hline $\begin{array}{l}\text { Longshore } \\
\text { sediment } \\
\text { transport }\end{array}$ & $\begin{array}{l}\text { The movement of sediments down- } \\
\text { coast in the surf zone by waves } \\
\text { breaking at an angle to the shoreline. }\end{array}$ & $\begin{array}{l}\text { Move sand around jetties and breakwaters. } \\
\text { Move sand over jetties into deposition areas. }\end{array}$ \\
\hline
\end{tabular}




\begin{tabular}{|l|l|l|}
\hline Component & Description & Function \\
\hline Sand bypassing & $\begin{array}{l}\text { The movement of beach sands across } \\
\text { a tidal inlet or river mouth by } \\
\text { mechanical dredging from up-coast } \\
\text { with placement down-coast. }\end{array}$ & $\begin{array}{l}\text { Prevent beach sediments from entering tidal } \\
\text { inlets. }\end{array}$ \\
\hline $\begin{array}{l}\text { Sediment } \\
\text { deposition }\end{array}$ & $\begin{array}{l}\text { The settling of sediment from the water } \\
\text { column where hydrodynamic forces are } \\
\text { insufficient to keep transported } \\
\text { material in suspension. }\end{array}$ & $\begin{array}{l}\text { Sedimentation tends to interfere with navigation } \\
\text { by causing shoaling in navigation channels and } \\
\text { reducing limiting depths. This process eventually } \\
\text { obstructs access to ports. }\end{array}$ \\
\hline Tides & $\begin{array}{l}\text { Diurnal or semidiurnal changes in sea } \\
\text { level caused by cyclical changes in the } \\
\text { gravitational pull of the moon and } \\
\text { inertia. }\end{array}$ & $\begin{array}{l}\text { High tides enable vessels with excess draft to } \\
\text { pass through navigation channels. Low tides } \\
\text { enable ships with excess air draft to pass under } \\
\text { bridges during low tide. }\end{array}$ \\
\hline Tidal propagation & $\begin{array}{l}\text { Water movement through bays, } \\
\text { estuaries, and inlets caused by the rise } \\
\text { and fall of tides. }\end{array}$ & $\begin{array}{l}\text { Affects the limiting depth in bays, estuaries, and } \\
\text { inlets and the distribution of sediment in } \\
\text { navigation channels. Changes in the way that } \\
\text { water moves may improve or impede navigation. }\end{array}$ \\
\hline $\begin{array}{l}\text { Surface water } \\
\text { runoff }\end{array}$ & $\begin{array}{l}\text { The unidirectional flow of water, } \\
\text { sediment, and nutrients from the land } \\
\text { toward the ocean. }\end{array}$ & $\begin{array}{l}\text { Carries sediment into the navigation channel } \\
\text { and may affect sedimentation and scouring } \\
\text { rates in navigation channels. }\end{array}$ \\
\hline Currents & $\begin{array}{l}\text { The directional flow of water in a } \\
\text { predictable pattern caused by a } \\
\text { gradient in temperature, salinity, or } \\
\text { bathymetry. }\end{array}$ & $\begin{array}{l}\text { How water flows through a water body influences } \\
\text { how sediment is distributed in the navigation } \\
\text { system. }\end{array}$ \\
\hline
\end{tabular}

Components and processes that support the navigation function(s) must be identified. Examples of components and processes that are typically found in navigation systems are listed in Table 3. In Table 3, components are distinguished from processes, but otherwise the list is in no particular order. Components and processes should be defined in ways that will support the analysis of resilience. For example, as noted in Table 3, jetties are defined as rubble-mound structures at a river mouth or a tidal inlet that are perpendicular to the coastline. Their primary function is to stabilize the navigation channel entrance and prevent longshore sediment from entering the inlet. Many components or processes could be identified at high resolution. The analyst will need to choose the best resolution, factoring in information about time and cost constraints that may limit an analysis. Again, for practical reasons, it will be necessary to limit the number of components and processes included in the analysis to those that are the most important to the particular navigation subsystem. This may include the components or process functions that are most vulnerable or most likely to fail when subjected to the loadings of a disturbance. 
Table 4. Examples of components and processes that are part of the storm damage reduction subsystem.

\begin{tabular}{|c|c|c|}
\hline Components & Description & Functions \\
\hline Barrier islands & $\begin{array}{l}\text { Elongated sand islands running parallel to } \\
\text { the coast. }\end{array}$ & $\begin{array}{l}\text { Protect the mainland shore from waves and } \\
\text { stabilize the shoreline by reducing the erosive } \\
\text { force of longshore currents. }\end{array}$ \\
\hline Beaches & $\begin{array}{l}\text { Sandy deposits of sediment located along } \\
\text { the coastline. }\end{array}$ & $\begin{array}{l}\text { Absorb wave energy and prevent storm surge } \\
\text { from advancing inland. }\end{array}$ \\
\hline Groins & $\begin{array}{l}\text { Rubble-mound or sheet pile structures } \\
\text { constructed perpendicular to the shoreline } \\
\text { and extending from the backshore across } \\
\text { the active littoral surf zone. }\end{array}$ & $\begin{array}{l}\text { Interrupts longshore sediment transport, } \\
\text { creating an accretion fillet to protect the up- } \\
\text { drift beach and causing erosion at the down- } \\
\text { drift beach. }\end{array}$ \\
\hline $\begin{array}{l}\text { Levees and } \\
\text { floodwalls }\end{array}$ & $\begin{array}{l}\text { Earthen dikes and concrete walls, generally } \\
\text { parallel with navigation channels and } \\
\text { floodways. }\end{array}$ & $\begin{array}{l}\text { Prevents flooding by confining river flows and } \\
\text { holding back storm surge. }\end{array}$ \\
\hline $\begin{array}{l}\text { Breakwaters } \\
\text { and multi- } \\
\text { purpose reefs }\end{array}$ & $\begin{array}{l}\text { Man-made rubble-mound or similar } \\
\text { structures in the surf zone parallel to the } \\
\text { coastline. }\end{array}$ & $\begin{array}{l}\text { Causes waves to break and spill, reducing } \\
\text { wave height and wave energy, reducing the } \\
\text { rate of beach erosion behind the structure. }\end{array}$ \\
\hline $\begin{array}{l}\text { Near-shore } \\
\text { berms }\end{array}$ & $\begin{array}{l}\text { Uncontaminated dredged material placed in } \\
\text { alongshore deposits in the surf zone. }\end{array}$ & $\begin{array}{l}\text { Provides a source of beach-building material } \\
\text { for beach stabilization and nourishment of } \\
\text { down-coast beaches. }\end{array}$ \\
\hline $\begin{array}{l}\text { Offshore } \\
\text { borrow areas }\end{array}$ & $\begin{array}{l}\text { Designated offshore sources of sand for } \\
\text { placement elsewhere in the system. }\end{array}$ & $\begin{array}{l}\text { Provides source of beach-building material for } \\
\text { pumping onto the beach to alleviate erosion. }\end{array}$ \\
\hline $\begin{array}{l}\text { Sand bypassing } \\
\text { plants }\end{array}$ & $\begin{array}{l}\text { Fixed mechanical dredging facility located at } \\
\text { the mouth of an inlet, river, or jetty. }\end{array}$ & $\begin{array}{l}\text { Moves beach sands across an inlet or a river } \\
\text { mouth. }\end{array}$ \\
\hline $\begin{array}{l}\text { Shore } \\
\text { protection } \\
\text { structures }\end{array}$ & $\begin{array}{l}\text { Concrete, steel, or rubble-mound stone hard } \\
\text { structures (e.g., bulkheads, seawalls, and } \\
\text { revetments) erected as a partial substitute } \\
\text { for natural protection when protective } \\
\text { beaches and sand dunes are destroyed or } \\
\text { overtopped. }\end{array}$ & $\begin{array}{l}\text { Protects a beach or sand dune that fronts } \\
\text { backshore from up-coast to alleviate down- } \\
\text { coast beach erosion to protect commercial or } \\
\text { residential development and other } \\
\text { infrastructure from flooding. }\end{array}$ \\
\hline $\begin{array}{l}\text { Storm surge } \\
\text { and tide barrier } \\
\text { dams }\end{array}$ & $\begin{array}{l}\text { Dams constructed in shallow water near } \\
\text { major economic and metropolitan areas, } \\
\text { with or without navigation gates. }\end{array}$ & $\begin{array}{l}\text { Protects low-lying regions from coastal storm } \\
\text { surge and tidal flooding. }\end{array}$ \\
\hline Wetlands & $\begin{array}{l}\text { Regions of land whose soil is saturated with } \\
\text { moisture, either permanently or seasonally. }\end{array}$ & $\begin{array}{l}\text { May reduce the height of waves and storm } \\
\text { surge and reduce wave energy. }\end{array}$ \\
\hline $\begin{array}{l}\text { Beach } \\
\text { nourishment }\end{array}$ & $\begin{array}{l}\text { Intentional placement of uncontaminated } \\
\text { dredged material on a beach, dune, barrier } \\
\text { island, or sand berm located in the near- } \\
\text { shore zone. }\end{array}$ & $\begin{array}{l}\text { Stabilize the location of an eroding beach, } \\
\text { dune, island, or berm. }\end{array}$ \\
\hline $\begin{array}{l}\text { Longshore } \\
\text { currents }\end{array}$ & $\begin{array}{l}\text { Directional flow of water in the surf zone } \\
\text { moving parallel to the coastline. }\end{array}$ & $\begin{array}{l}\text { Cause erosion or accretion along beaches } \\
\text { and barrier islands that affect the degree of } \\
\text { protection from high tides and storm surge. }\end{array}$ \\
\hline $\begin{array}{l}\text { Erosion and } \\
\text { accretion }\end{array}$ & $\begin{array}{l}\text { Movement of sand or sediment by } \\
\text { hydrodynamic forces. }\end{array}$ & $\begin{array}{l}\text { Causes depletion or accumulation of sand or } \\
\text { sediments along beaches, at barrier islands, } \\
\text { and in the surf zone, affecting the level of } \\
\text { protection from high tides and storm surge. }\end{array}$ \\
\hline
\end{tabular}




\begin{tabular}{|l|l|l|}
\hline Components & Description & Functions \\
\hline $\begin{array}{l}\text { Longshore } \\
\text { sediment } \\
\text { transport }\end{array}$ & $\begin{array}{l}\text { Movement of sediments down-coast in the } \\
\text { surf zone from waves breaking in a } \\
\text { dominant direction at an angle to the } \\
\text { shoreline. }\end{array}$ & $\begin{array}{l}\text { Nourishes down-drift beaches from depletion } \\
\text { of sediment source by maintaining sediment } \\
\text { transport balance. }\end{array}$ \\
\hline Sand bypassing & $\begin{array}{l}\text { Artificial movement of beach sands across a } \\
\text { tidal inlet or river mouth by mechanical } \\
\text { dredging from up-coast with placement } \\
\text { down-coast. }\end{array}$ & $\begin{array}{l}\text { Nourishes down-drift beaches with sediment } \\
\text { that has accumulated at up-coast jetty fillets. }\end{array}$ \\
\hline $\begin{array}{l}\text { Surface water } \\
\text { runoff }\end{array}$ & $\begin{array}{l}\text { The unidirectional flow of water, sediment, } \\
\text { and nutrients from the land to the ocean. }\end{array}$ & $\begin{array}{l}\text { Transfers water that might cause flooding } \\
\text { from developed areas to undeveloped areas } \\
\text { (i.e., ocean). }\end{array}$ \\
\hline Tides & $\begin{array}{l}\text { Diurnal or semidiurnal changes in sea level } \\
\text { caused by cyclical changes in the } \\
\text { gravitational pull of the moon and inertia. }\end{array}$ & $\begin{array}{l}\text { Tides may effectively alter the amount of } \\
\text { surge realized during coastal storms. High } \\
\text { tides tend to increase the effects of storm } \\
\text { surge. Low tides tend to reduce the effect. } \\
\text { Tides also determine the elevation at which } \\
\text { waves will erode beaches and dunes. }\end{array}$ \\
\hline
\end{tabular}

Table 5. Components and processes that are part of an ecosystem restoration subsystem defined by an oyster restoration project.

\begin{tabular}{|l|l|l|}
\hline Components & Description & Functions \\
\hline Oysters & Sessile, filter-feeding organisms. & Growth and reproduction. \\
\hline Habitat & $\begin{array}{l}\text { Geographic areas that possess features that will } \\
\text { satisfy the life requisites of a population in whole } \\
\text { or in part. }\end{array}$ & $\begin{array}{l}\text { Provide a location where organisms } \\
\text { can grow and reproduce. }\end{array}$ \\
\hline Processes & Source of nourishment for oysters. & $\begin{array}{l}\text { Provide energy for growth and } \\
\text { reproduction. }\end{array}$ \\
\hline Tides & Description & Functions \\
\hline Currents & $\begin{array}{l}\text { Diurnal or semidiurnal changes in sea level } \\
\text { caused by cyclical changes in the gravitational } \\
\text { pull of the moon and inertia. }\end{array}$ & $\begin{array}{l}\text { Transport salt water and nutrients into } \\
\text { the estuary and remove waste. }\end{array}$ \\
\hline $\begin{array}{l}\text { Surface water } \\
\text { runoff }\end{array}$ & $\begin{array}{l}\text { The directional flow of water in a predictable } \\
\text { pattern caused by a gradient in temperature, } \\
\text { salinity, or other physical phenomenon. }\end{array}$ & $\begin{array}{l}\text { Ristribute food and nutrients within the } \\
\text { estuary in a predictable pattern. }\end{array}$ \\
\hline nutrients and pollutants to the estuary. & $\begin{array}{l}\text { Transfer sediment and nutrients from } \\
\text { the land to the estuaries, bays, and } \\
\text { inlets. }\end{array}$ \\
\hline Sedimentation & $\begin{array}{l}\text { The settling of sediment from the water column } \\
\text { and its accumulation at the bottom of estuaries, } \\
\text { bays, and inlets. }\end{array}$ & $\begin{array}{l}\text { Sedimentation may reduce or block } \\
\text { the flow of water through the filter- } \\
\text { feeding mechanisms of oysters and } \\
\text { reduce growth and reproduction. }\end{array}$ \\
\hline
\end{tabular}


To analyze the resilience of the navigation subsystem with respect to permitting access for vessels of a particular class, it is necessary to develop fragility curves for each component or process function. For example, if a coastal storm were to damage the jetty, this could impede navigation by causing shoaling or migration of the channel. The analyst must specify a critical level of shoaling or migration that would impede navigation for the vessel class and specified draft of interest. A fragility curve for the jetty's function with respect to providing navigation for a particular vessel class would describe the probability that the critical level of shoaling or migration sufficient to impede navigation by that particular class of vessel occurred as a result of the storm.

\section{Storm damage reduction subsystem}

The primary function of the storm damage reduction subsystem is to reduce the probability of economic losses arising from coastal storms. A suitable performance measure for the storm damage reduction system as a whole is the expected economic loss avoided. Examples of components and processes that are typically associated with storm damage reduction subsystems are listed and briefly described in Table 4. For example, barrier islands are elongated sand islands that run parallel to the coast. Their function with respect to storm damage reduction is to protect the mainland shore from waves and stabilize the shoreline by reducing the erosive force of longshore currents. These two functions are distinct. If both functions of barrier islands are important in an ICS, an analysis of resilience should treat both of these two functions separately.

When a single component or process has multiple functions, at least one fragility curve is needed for each function unless the critical state of the component is the same for each function. For example, a barrier island protects the mainland from waves during storm events. The fragility curve for barrier island function might estimate the probability that wave force on the protected side of the island is less than some critical amount of wave force needed to prevent erosion during a storm. Alternatively, the fragility curve might estimate the probability that the volume of sediment eroded during the course of wave attack is less than that required to maintain the desired level of protection for the mainland. Barrier islands also function to stabilize the shoreline by preventing the longshore currents from eroding beach sand. A fragility curve for the beach stabilization function might estimate the probability that the barrier island would remain intact through the storm so that erosive forces at the beach remain below some critical 
level to prevent net loss of sand from the protected beach following the storm.

\section{Ecological restoration subsystem}

The objective of USACE ecosystem restoration projects is "to restore degraded ecosystem structure, function, and dynamic processes to a less degraded, more natural condition" (USACE 2000, ER-1105-2-100). To meet this objective, a variety of different types of ecosystem restoration projects might be undertaken by USACE. For example, these projects might involve the construction of breakwaters, flow diversions, and other engineered structures to control the flow of water. Other projects, such as oyster restoration, might be designed to re-establish fauna. Still other projects might seek to reduce contaminant concentrations through monitored natural recovery of sediments, which involves no specific action other than monitoring.

The resilience of an ecosystem restoration subsystem consisting of multiple projects should be assessed at the project level. Each project has unique performance objectives and, occasionally, the two performance objectives may conflict, or changes in boundary conditions may have opposing effects (positive or negative) on the performance of different types of ecosystem restoration projects. Managing for the resilience of a broad, poorly defined ecosystem restoration objective may lead to suboptimal results (Walker and Salt 2006).

Once measures of resilience are calculated for each project, they can then be aggregated as described in Equation 17 to obtain a single measure of resilience for the ecosystem restoration subsystem as a whole. For example, the objectives for an oyster restoration project might be expressed in terms of the desired level of oyster production each year and the objectives for a wetland restoration project might be expressed in terms of the number of wetland habitat acres maintained during the year or some measure of primary productivity during the year. If these are the only ecosystem restoration projects in the ICS, they can be aggregated to estimate resilience of the subsystem.

Components and processes that support an ecosystem restoration project must be identified at a project level and individual ecosystem restoration projects may themselves be treated as components of an ecosystem restoration system. For the purpose of providing an example, consider an 
oyster restoration project for which the purpose is to create suitable oyster habitat in an estuary and seed oyster beds to produce a sustainable quantity of oysters. Table 5 lists examples of components and processes that might be considered in estimating the resilience of this project. The functional performance of this project over time may depend upon the persistence of natural processes such as currents that deliver food, oxygen, and water of sufficient quality to the oyster beds. Low rates of sedimentation may be needed to prevent smothering of the oyster beds. If these processes are vulnerable to an interruption caused by an extreme event, such as a coastal storm that temporarily or permanently modifies the currents so that food and oxygen are redistributed in the estuary or that causes excess sedimentation in the oyster bed, the ecosystem restoration project may not achieve its functional performance objective over time. The fragility curve for each component or process function will describe the probability that a coastal storm would disrupt component or process functions so that oyster production and/or reproduction fall below some critical level that is needed to sustain project benefits. For example, a coastal storm could cause changes in bathymetry that result in changes in the currents and reduce food supply or increase sedimentation rates.

There is a necessary distinction between the components and processes of an ecosystem and the components and processes of an ecosystem restoration project. Oysters can themselves be understood as components of an estuarine ecosystem that function to improve water quality, transfer nutrients from the water column to the sediments, and increase the complexity of habitat for other organisms. However, USACE does not manage the ecosystem, only the ecosystem project. Therefore, it is assumed that an analysis of resilience by USACE should focus specifically on robustness and rapidity of the ecosystem restoration project rather than on the engineering resilience of the ecosystem as a whole. If there are multiple ecosystem restoration objectives for a single project, a resilience measure should be estimated for each objective and these can then be aggregated to obtain a measure of resilience for the project. 


\section{Critical Processes Associated with Sea- level Rise that may Influence Resilience}

An evolutionary force is a gradual and persistent change in boundary conditions that may affect both functional performance and resilience. Evolutionary processes occur on much longer time scales than disturbances. Sea-level rise is an evolutionary process that may affect the functional performance of components and processes. While the effects of sea-level rise may appear to be very similar to the effects described for storm surge, they are sustained for much longer periods of time and, as a result, may lead to very different effects. In addition, when a disturbance of a particular magnitude is superimposed on these changes, the effects of disturbance may be more (or less) severe. Tables 6 and 7 anticipate the effects that sealevel rise might have on the functional performance of components and processes of navigation and storm damage reduction subsystems. The third columns of Tables 6 and 7 describe whether or not a positive (+) or a negative (-) effect on resilience is anticipated. The symbol $+/-$ means that, at this level of generality, it is unclear whether the effect on the component or process function will cause an improvement or degradation of resilience. This lack of clarity about the effect arises because that effect will depend upon site-specific factors.

A number of evolutionary processes associated with sea-level rise may influence resilience and appear repeatedly in Tables 6 and 7. In general, this suggests that particular attention should be given to these processes in an analysis of ICS resilience. Many of these processes are interrelated. They include:

- Changes in water and storm surge elevations.

- Changes in wave climate.

- Changes in patterns of shoreline erosion and accretion.

- Changes in patterns of sediment scour, deposition, and shoaling.

- Changes in longshore currents and patterns of longshore sediment transport.

- Changes in tidal prism and tidal propagation.

- Changes in the location of the tidal wedge and estuarine salinity.

- Changes in bathymetry.

- Changes in surface water retention capacity.

- Changes in surface water runoff. 
Table 6. Effect of sea-level rise on components and processes of the navigation subsystem.

\begin{tabular}{|c|c|c|}
\hline Component & Effect of Sea-level Rise & Effect \\
\hline Jetties & $\begin{array}{l}\text { Increases in water depth and wave height may lead to the formation of larger } \\
\text { fillets with material passing over sediment barriers into navigation channels. } \\
\text { Greater down-drift erosion may cause jetty flanking. }\end{array}$ & - \\
\hline $\begin{array}{l}\text { Navigation } \\
\text { channels }\end{array}$ & $\begin{array}{l}\text { Increases in channel depth may enable vessels with deeper drafts to access } \\
\text { ports. The saltwater boundary may advance inland, increasing shoaling rates and } \\
\text { altering the location of shoals in navigation channels. }\end{array}$ & $+/-$ \\
\hline $\begin{array}{l}\text { Port } \\
\text { infrastructure }\end{array}$ & $\begin{array}{l}\text { Increases in the rate of shoaling in berthing areas along piers, wharves, and } \\
\text { bulkheads. Decreases in the level of protection afforded to port infrastructure by } \\
\text { storm surge barriers such as breakwaters and floodwalls. }\end{array}$ & - \\
\hline Turning basins & $\begin{array}{l}\text { Increases in fine-grain shoaling within turning basins may lead to increases in the } \\
\text { turbidity of water in the wakes caused by ship propellers. Tidal current velocities } \\
\text { may reduce maneuverability in turning basins. }\end{array}$ & - \\
\hline Bridges & $\begin{array}{l}\text { Increases in water depth will result in a corresponding reduction in the air draft } \\
\text { under bridges. }\end{array}$ & - \\
\hline $\begin{array}{l}\text { Offshore disposal } \\
\text { sites }\end{array}$ & $\begin{array}{l}\text { Sediment contained in uncapped disposal sites may become dispersed more } \\
\text { easily. This may lead to increases in dredged material capacity at the disposal site } \\
\text { or increases in the rate of shoaling in navigation channels. }\end{array}$ & + \\
\hline $\begin{array}{l}\text { Beneficial use } \\
\text { placement }\end{array}$ & $\begin{array}{l}\text { Higher waves and stronger longshore currents may increase the rate of erosion at } \\
\text { beaches and near-shore berms. This may increase the need for dredged material } \\
\text { disposal capacity at beneficial use placement sites. }\end{array}$ & + \\
\hline $\begin{array}{l}\text { Confined disposal } \\
\text { facilities (CDFs) }\end{array}$ & $\begin{array}{l}\text { Near-shore and island CDFs containing dredged material from navigation } \\
\text { channels will experience greater water depths, more potential for overtopping, and } \\
\text { greater wave loading on protective revetments. }\end{array}$ & - \\
\hline Locks & $\begin{array}{l}\text { In general, no impact on navigation operations at locks is expected because most } \\
\text { are located at elevations above which the influence of tidal action will be minimal } \\
\text { or non-existent. }\end{array}$ & $+/-$ \\
\hline Navigation gates & $\begin{array}{l}\text { Increases in water depth at navigation gates are expected to lead to } \\
\text { corresponding increases in storm surge elevations, reducing the level of protection } \\
\text { provided by navigation gates that are built into storm surge barriers. }\end{array}$ & - \\
\hline Near-shore berms & $\begin{array}{l}\text { Increases in rates of erosion at near-shore berms may increase the need for } \\
\text { beach nourishment and increase dredged material placement capacity at } \\
\text { beneficial use placement sites. Increases in the movement of sediment in the surf } \\
\text { zone may increase the potential for waves to move material onshore to nourish } \\
\text { beaches naturally. }\end{array}$ & + \\
\hline Breakwaters & $\begin{array}{l}\text { Increases in water depth and wave loading at breakwaters will increase the } \\
\text { probability of overtopping and economic loss to port infrastructure on the } \\
\text { protected side of breakwaters. }\end{array}$ & - \\
\hline Process & Effect of Sea-level Rise & Effect \\
\hline $\begin{array}{l}\text { Dredged material } \\
\text { disposal }\end{array}$ & $\begin{array}{l}\text { Increases in the rate of sedimentation in navigation channels may increase the } \\
\text { need for dredged material disposal capacity. }\end{array}$ & - \\
\hline Dredging & $\begin{array}{l}\text { Increases in erosion caused by longshore currents could increase the amount of } \\
\text { shoaling in navigation channels, requiring an increase in the frequency and } \\
\text { intensity of dredging required to maintain a limiting depth. }\end{array}$ & - \\
\hline
\end{tabular}




\begin{tabular}{|c|c|c|}
\hline Process & Effect of Sea-level Rise & Effect \\
\hline $\begin{array}{l}\text { Longshore } \\
\text { sediment } \\
\text { transport }\end{array}$ & $\begin{array}{l}\text { Increases in water depth in the surf zone may result in higher waves, increases in } \\
\text { the height at which waves break, and increases in movement of sediment within } \\
\text { the surf zone. This may cause sediment to move around the end of jetties into } \\
\text { navigation channels. }\end{array}$ & - \\
\hline Sand bypassing & $\begin{array}{l}\text { Increased sediment transport in the surf zone suggests that the size of up-drift } \\
\text { fillets may increase and that the volume of sand transported over jetty walls into } \\
\text { navigation channels may increase. This may increase the need for sand bypassing } \\
\text { capabilities. }\end{array}$ & |- \\
\hline $\begin{array}{l}\text { Sediment } \\
\text { deposition }\end{array}$ & $\begin{array}{l}\text { An increase in water depth and inland advancement of the saltwater boundary } \\
\text { may increase the rate of fine-grained sediment deposition in navigation channels } \\
\text { and alter the location of shoals. }\end{array}$ & $+/-$ \\
\hline Tidal propagation & $\begin{array}{l}\text { Higher mean tide elevation will cause tidal currents to propagate further into the } \\
\text { navigation waterway, potentially affecting the maneuverability of ships in ports, } \\
\text { turning basins, and navigation channels. }\end{array}$ & - \\
\hline Tides & $\begin{array}{l}\text { Tide levels and salinity wedge will propagate further up-channel, causing fine-grain } \\
\text { sediments to flocculate and settle out of the water column and greater shoaling in } \\
\text { the navigation channel. }\end{array}$ & - \\
\hline $\begin{array}{l}\text { Surface water } \\
\text { runoff }\end{array}$ & $\begin{array}{l}\text { Increases in water elevation are not expected to affect surface water runoff on a } \\
\text { large scale, but local effects may be observed near the landward limits of the tidal } \\
\text { boundary. }\end{array}$ & $+/-$ \\
\hline Currents & $\begin{array}{l}\text { River currents will be largely unaffected, except near entrances to rivers where the } \\
\text { salinity wedge will tend to cause fine-grained sediments to cause shoaling in } \\
\text { navigable waterways. Longshore currents may increase as breaking wave angles } \\
\text { increase with water depth, creating the potential for increased sedimentation in } \\
\text { inlets. }\end{array}$ & $+/-$ \\
\hline
\end{tabular}

Table 7. Effect of sea-level rise on components and processes of the storm damage reduction subsystem.

\begin{tabular}{|l|l|l|}
\hline Component & Effect of Sea-level Rise & Effect \\
\hline Barrier islands & $\begin{array}{l}\text { Sea-level rise will alter patterns of longshore currents and may affect sand } \\
\text { deposition rates, resulting in changes in the net gain or loss of sand from the } \\
\text { island and the stability of the island. Barrier islands may become more or } \\
\text { less vulnerable to acute erosion during coastal storm events. }\end{array}$ & $+/-$ \\
\hline Beaches & $\begin{array}{l}\text { Deeper water, higher waves, and changes in longshore currents may alter } \\
\text { rates of erosion or accretion. A net loss of sediment may lead to increased } \\
\text { requirements for beach nourishment. Changes in the structure of a beach } \\
\text { may alter its effectiveness as a wave absorber and as a storm surge barrier. }\end{array}$ & $+/-$ \\
\hline Groins & $\begin{array}{l}\text { An increase in longshore sediment transport caused by sea-level rise may } \\
\text { result in more groin filling and less erosion down-drift of groins. }\end{array}$ & + \\
\hline $\begin{array}{l}\text { Levees and } \\
\text { floodwalls }\end{array}$ & $\begin{array}{l}\text { Increase in storm surge elevations on floodwalls and levees under tidal } \\
\text { influence will tend to result in higher probabilities of overtopping, toe erosion, } \\
\text { seepage, and breaching. }\end{array}$ & - \\
\hline $\begin{array}{l}\text { Breakwaters and } \\
\text { multi-purpose reefs }\end{array}$ & $\begin{array}{l}\text { Increases in water levels will result in corresponding increases in wave height } \\
\text { relative to structures and wave energy, leading to increased rates of beach } \\
\text { erosion along the protected shoreline. }\end{array}$ & - \\
\hline
\end{tabular}




\begin{tabular}{|c|c|c|}
\hline Component & Effect of Sea-level Rise & Effect \\
\hline Near-shore berms & $\begin{array}{l}\text { Changes in longshore currents could alter rates of erosion and accretion at } \\
\text { near-shore berms. Increased rates of near-shore berm erosion will increase } \\
\text { the capacity for dredged material placement. Reductions in the size of near- } \\
\text { shore berms will create greater potential for waves to move material onshore } \\
\text { beneficially. }\end{array}$ & $+/-$ \\
\hline $\begin{array}{l}\text { Offshore borrow } \\
\text { areas }\end{array}$ & $\begin{array}{l}\text { Increases in water depth may have little impact on offshore borrow areas that } \\
\text { provide a supply of sand for beach nourishment projects. }\end{array}$ & $+/-$ \\
\hline $\begin{array}{l}\text { Sand bypassing } \\
\text { plants }\end{array}$ & $\begin{array}{l}\text { Increases in water elevation may lead to increases in the frequency and } \\
\text { intensity of flooding at permanently fixed sand bypassing facilities. Mobile } \\
\text { plants will need to be relocated to avoid flooding more frequently. }\end{array}$ & - \\
\hline $\begin{array}{l}\text { Shore protection } \\
\text { structures }\end{array}$ & $\begin{array}{l}\text { Wave loads on shore protection structures (bulkheads, seawalls, and } \\
\text { revetments) may increase, increasing the potential for toe erosion, } \\
\text { overtopping, and erosion behind these structures. }\end{array}$ & - \\
\hline $\begin{array}{l}\text { Storm surge and } \\
\text { tide barrier dams }\end{array}$ & $\begin{array}{l}\text { Increases in water depth will lead to higher storm surge elevations relative to } \\
\text { the crest of storm surge and tide barriers, leading to increases in the } \\
\text { probability of overtopping and structural failure. }\end{array}$ & - \\
\hline Wetlands & $\begin{array}{l}\text { Gradual increases in water level of wetlands will increase spatial area of bays } \\
\text { and estuaries and enhance floodwater retention capacity. Inundation of the } \\
\text { seaward edge of coastal wetlands may transform these wetlands to open- } \\
\text { water systems. }\end{array}$ & $+/-$ \\
\hline Processes & Effect of Sea-level Rise & Effect \\
\hline Beach nourishment & $\begin{array}{l}\text { Changes in sea level may affect rates of erosion and accretion on beaches, } \\
\text { resulting in increases or decreases in the need for beach nourishment } \\
\text { projects to stabilize shorelines. }\end{array}$ & $+/-$ \\
\hline Longshore currents & $\begin{array}{l}\text { Longshore currents may increase as breaking wave angles increase with } \\
\text { water depth, altering patterns of erosion and accretion on beaches. }\end{array}$ & $+/-$ \\
\hline Erosion/accretion & $\begin{array}{l}\text { Increases in water elevation may tend to increase rates of erosion water and } \\
\text { waves impinge at higher elevations on barrier islands, beaches, and dunes. }\end{array}$ & $+/-$ \\
\hline $\begin{array}{l}\text { Longshore sediment } \\
\text { transport }\end{array}$ & $\begin{array}{l}\text { Increases in water depth will tend to increase the height of breaking waves } \\
\text { and increase the quantity of sediment that is transported down-coast in the } \\
\text { surf zone. }\end{array}$ & - \\
\hline Sand bypassing & $\begin{array}{l}\text { Increases in water elevation that increase the volume of sediment } \\
\text { transported in the surf zone may lead to greater up-drift fillet formation, } \\
\text { increasing the need for and intensity of sand bypassing capacity. }\end{array}$ & - \\
\hline Surface water runoff & $\begin{array}{l}\text { Increases in water elevations will tend to push regions of tidal influence } \\
\text { upstream in watersheds. }\end{array}$ & \\
\hline Tides & $\begin{array}{l}\text { Tide levels and salinity wedge will propagate further up-channel, causing fine- } \\
\text { grain sediments to flocculate and settle out of the water column, creating } \\
\text { greater shoaling. }\end{array}$ & - \\
\hline
\end{tabular}




\section{Non-probabilistic Indicators of Engineering Resilience}

Probabilistic measures of engineering resilience introduced in Chapter 4 may require a substantial effort to calculate. If time and cost constraints do not permit the level of analysis required to estimate a probabilistic measure of engineering resilience, a non-probabilistic indicator may be sought. In contrast to a probabilistic measure of engineering resilience, which is the joint probability of meeting robustness and rapidity objectives given the severity of an event, non-probabilistic indicators of robustness and rapidity are assessed independently of one another. Non-probabilistic indicators of engineering resilience may be direct or indirect. Direct indicators of engineering resilience describe how well the system responds to a disturbance in terms of system performance objectives or the length of time required to restore system performance. Indirect (or proxy) indicators of engineering resilience describe characteristics of the system that are somehow thought to be correlated to robustness and rapidity.

Clearly articulated performance objectives must be specified for the system prior to selecting direct and indirect indicators of resilience. Although objectives are central to nearly every element of project decision making, environmental and water resource managers often fail to adequately state their objectives (Slocombe 1998, Gregory and Keeney 2002). For example, consider an ecosystem restoration subsystem. An objective that is articulated as "improve ecological health" is useless with respect to identifying indicators of resilience because it is ambiguous. A more specific objective would target a particular project and outcome. For example, if an oyster restoration project is a component of the subsystem, a well-specified objective might be articulated as follows: "Re-establish a sustainable population of native oysters in the ICS to levels documented in 1900." This provides not only a clear definition of the resource, but also a direction of preference and a threshold for determining success or failure of the project. Similarly, consider a navigation subsystem. An objective that is articulated as follows: "Provide commercial and recreational vessels with access to port $\mathrm{X}$ " would not be sufficient to identify direct and indirect indicators of resilience. It is also necessary to specify the class, size, shape, and draft of 
vessels for which access will be provided and, perhaps, the tidal periods during which access should be available.

\section{Direct indicators}

Direct indicators of resilience describe system performance during a disturbance (robustness) or the length of time to recovery of the predisturbance performance level following a disturbance event (rapidity). Direct indicators of robustness are expressed in units of system output consistent with system performance objectives. Direct indicators of rapidity are expressed in units of time. The information needed to assess indicators of engineering resilience can be gathered through direct observation of system performance, through historical records of system performance, or through the use of simulation models.

As in the case of a probabilistic measure of resilience, a determination of engineering resilience using direct indicators requires system managers to specify how well the system should perform and how quickly it should recover from an event of a particular magnitude. A system is resilient if its performance is acceptable in terms of both robustness and rapidity criteria and is not resilient otherwise. Alternatively, a ratio of actual performance and the critical performance level for which the system is being managed might be used to distinguish between those systems that perform much better or worse than those that perform only slightly better or worse than they should.

The primary difference between the probabilistic measure of resilience and the direct indicator of resilience is that it contains no information on the uncertainty in robustness or rapidity of the system. As with the probabilistic measure of resilience, system performance and rapidity are assessed for each possible level of disturbance severity. If the probability of each potential level of severity is known, then one can calculate an expected value for the direct indicators for robustness and rapidity.

$$
E\left[I_{D}\right]=\sum_{m} p(m) I_{D}(m)
$$

The variable $I_{D}$ is the direct indicator of robustness or rapidity, which is a function of event severity, and $p(m)$ is the probability of the event severity. It would also be possible to calculate an overall measure of resilience as in Equation 16. However, because uncertainty in robustness and rapidity is 
not being considered, this seems likely to overestimate resilience. ${ }^{1}$ Therefore, this option is not considered here as a possible approach.

In general, direct indicators of resilience will be developed in the course of developing a probabilistic measure of resilience. This can be seen in Figure 3, in which the robustness indicator corresponds to system performance $Q$ and the rapidity indicator corresponds to $r$. The basic difference between the two approaches is that there is no analysis of uncertainty in system performance and recovery. While the probabilistic measure of resilience requires more effort to develop, it culminates in a characterization of resilience that is unified over the robustness and rapidity dimensions. The non-probabilistic approach culminates in characterizations of robustness and rapidity that must be interpreted independently.

An example of a direct indicator of robustness for an electric utility in a coastal area might be the fraction of utility customers that lose power during a coastal storm. A direct indicator of rapidity might be the number of hours or days required to restore power to those customers following the storm. Similarly, a direct indicator of navigation subsystem robustness might be the limiting depth of a navigation channel following a storm and an indicator of rapidity might be the length of time required to restore the pre-disturbance limiting depth in the navigation system following a coastal storm. The navigation subsystem is deemed resilient if both the robustness and rapidity objectives are met.

\section{Indirect indicators}

Indirect indicators of engineering resilience describe characteristics of a system that are assumed to be correlated with the robustness or rapidity of the system. The primary advantage of these indicators is that they can be evaluated without observing how the system actually performs during a disturbance. Thus, they can be assessed at any time. The primary disadvantage of indirect indicators is that the strength of their relationship

\footnotetext{
${ }^{1}$ It would also be possible to calculate the probability of acceptable performance as in Equation 16 . This results in a single measure of resilience that is a probability of acceptable performance over all potential levels of event severity. However, because uncertainty in robustness and rapidity are not being considered, $\mathrm{p}\left(\mathrm{A}_{\mathrm{i}} \mid \mathrm{m}\right) \in[0,1]$. If in fact there is uncertainty in robustness and rapidity, then the probability of acceptable performance will tend to be over-estimated. Since it is anticipated that these uncertainties may be rather large, measures of resilience obtained from direct indicators may significantly overestimate probabilistic measures of resilience.
} 
with robustness or rapidity may be weak or unclear. As with the probabilistic measure of resilience and direct indicators of robustness and rapidity, critical levels of the indicator are needed to assess whether robustness and rapidity objectives have been met. In general, it seems that these criteria may be much more difficult to identify in terms of an indirect indicator than in terms of a direct indicator. This makes indirect indicators of resilience more difficult to interpret.

An indirect indicator of the robustness of a storm damage reduction system to coastal storm surge might be the number of lines of defense (e.g., tide barriers, levees, etc.) between the protected property and the shoreline. In this case, there is an assumed relationship between the robustness of a storm damage reduction system and the number of lines of defense within the system. However, it seems more difficult to say exactly how many lines of defense a storm damage reduction system should have to satisfy robustness objectives. An indirect indicator of the rapidity of the storm damage reduction system might be the availability of contractors who could restore the design level of protection, given structural failure of the storm damage reduction system. Again, it is difficult to say how many contractors should be available in order to satisfy rapidity objectives for the system.

An indirect indicator of the robustness of an oyster restoration project to disease might be the genetic diversity in the oyster population. An indirect indicator of rapidity of the oyster restoration project might be the distance between neighboring oyster beds that might provide a source of oyster larvae to recolonize those beds that have been decimated by disease. As with direct indicators of resilience, the interpretation of indirect indicators requires that some critical level of that indicator be chosen as a basis for interpreting whether or not a system exhibits resilience. For example, suppose that natural recolonization of the oyster bed could be expected to occur within three to six months if located 1 mile from a neighboring oyster bed, 1 year if located 5 miles from a neighboring oyster bed, or 5 years if located 10 miles from a neighboring oyster bed. System managers must determine a maximum acceptable period between decimation and recolonization and then convert this to a critical distance.

\section{Critical levels for robustness and rapidity indicators}

The choice of critical robustness or rapidity levels will reflect management objectives for the system of interest. For example, consider a navigation subsystem. A stringent criterion for assessing whether the system is robust 
against a disturbance might be to provide access for vessels with a $50-\mathrm{ft}$ draft during a 2-hr period at high tide twice a day. However, if only a handful of vessels with $50-\mathrm{ft}$ drafts are entering the port each year, then the net benefit of managing the system for resilience to a storm of a rare magnitude may be negative. In this case, an economic argument might be made for making the robustness criteria less stringent. Management objectives should reflect an economic tradeoff between the benefits of satisfying resilience objectives and the cost of interrupting and recovering system performance. Robustness and rapidity criterion may also vary over time. For example, consider an oyster restoration project for which the performance objective is assessed in terms of the oyster reproduction rate or oyster colonization rate in the ICS. A critical level of performance used in determining robustness may vary with the natural reproductive cycle of oysters, with lower performance thresholds adopted during the nonbreeding season.

\section{Multiple objectives for system performance}

In many cases, an ICS may be managed to achieve multiple objectives. For example, an ecosystem restoration subsystem may consist of a portfolio of ecosystem restoration projects including wetlands restoration projects, oyster restoration projects, and contaminant remediation projects. Similarly, a navigation subsystem may provide access to several different classes of vessels with distinctly different navigation requirements. In these cases, indicators of resilience must be identified and evaluated with respect to each objective independently. These indicators may be somehow aggregated to assess the resilience of the subsystem as a whole. If some objectives are neglected, management decisions to improve resilience may result in a net loss through unintended or unmeasured trade-offs (Walker and Salt 2006). For instance, managing for the resilience of a navigation subsystem alone could lead to straightening of rivers, which could unintentionally reduce the resilience of ecosystem restoration projects.

\section{Selecting indicators of resilience}

Numerous techniques for selecting metrics to aid decision making have been proposed (e.g., Suter 2001, Dale and Beyeler 2001, Keeney and Gregory 2005, Reichert et al. 2007). A recent synthesis of these techniques promotes a three-step process for selecting indicators of ecosystem restoration project performance once ecosystem restoration performance objectives have been specified: 1) identify the metric type (natural, 
constructed, or proxy); 2) assess the properties of the metric; and 3) document the process used to select, evaluate, and assess the metric. Although the approach is described here as a linear three-step process, this process is almost always an iterative one that may require input from multiple stakeholders and disciplinary viewpoints.

When selecting indicators of resilience, consideration should be given to the directness of the link between the metric and management objectives. Keeney and Gregory (2005) describe a hierarchy of metric types that vary with respect to their relationship to objectives:

1. Natural metrics (direct indicators) measure the degree to which an objective is met in terms of the objective itself. These metrics can typically be assessed by observing a system and counting or physically measuring system performance. These metrics are widely understood and their relationship to an objective is transparent and valid on its face.

2. Constructed metrics are scales developed to measure the degree to which an objective is met when no natural metric exists to measure progress toward that objective.

3. Proxy metrics (indirect indicators) measure the degree to which an objective is met in terms other than the objective itself. Like natural metrics, these can typically be assessed by observing a system and counting or physically measuring some characteristic of the system.

Natural metrics are always preferred to constructed and proxy metrics because they are widely understood, transparent, and there is no uncertainty regarding their relationship to system performance objectives. Keeney and Gregory (2005) suggest that, in the absence of a natural metric, it may be better to construct a metric than to use a proxy metric, but close attention should be given to how the metric is constructed. Proxy metrics are least preferred because the strength of the relationship to system performance objectives is often unclear.

The differences among the three types of metrics can be seen in an example for an ecosystem restoration project. Consider, again, an oyster restoration project for which the performance objective is to re-establish a sustainable population of native oysters to levels documented in 1900. A natural metric of project performance is the oyster population and, perhaps, the acreage of oyster beds in the project area. If estimates of the population size or oyster bed acreage cannot be obtained, it is possible to construct a metric that integrates available information. For example, a qualitative population scale 
might be constructed with three levels (high, medium, or low) and evaluated by experts based on their observations in the absence of a population survey. In practice, constructed metrics can be more elaborate than these (Keeney and Gregory 2005). Proxy metrics may be even less desirable than a well-designed constructed metric. For example, because a secondary objective of oyster restoration is to improve water quality, changes in water quality might be used as a proxy for changes in oyster populations. However, if the strength of the correlation between the population of oysters and physical measures of water quality is weak, this proxy metric might be less preferred than the constructed indicator.

Indicators of resilience and other metrics should be evaluated against a set of desirable properties (Keeney and Gregory 2005). These properties are described in Table 8. Relevant metrics capture information about system performance objectives at appropriate spatial and temporal scales. Unambiguous metrics clearly associate each level of the metric with each potential level of system performance. Comprehensive metrics span the full range of potential system performance outcomes. Direct metrics are expressed in units of system performance. Operational metrics can be assessed, forecasted, and monitored given available resources. Transparent metrics are easily understood. It is also important to document how an indicator was selected and evaluated so that, in the future, results of the analysis can be interpreted and continuity in management decision-making can be maintained. Archiving of documentation and data on indicators of resilience in repositories (e.g., libraries, corporate databases, websites, etc.) can increase the use and impact of a given indicator (McKay et al. 2010).

Table 8. Desirable properties of metrics (after Keeney and Gregory (2005), McKay et al. (2010)).

\begin{tabular}{|l|l|}
\hline Property & Description \\
\hline Relevant & $\begin{array}{l}\text { The metric captures information about system performance objectives at appropriate } \\
\text { spatial and temporal scales. }\end{array}$ \\
\hline Unambiguous & $\begin{array}{l}\text { There is no ambiguity regarding what value of the metric corresponds to what level of } \\
\text { system performance. }\end{array}$ \\
\hline Comprehensive & The range of the metric spans the full range of potential system performance outcomes. \\
\hline Direct & $\begin{array}{l}\text { The metric is expressed in terms that are identical to the way that system performance } \\
\text { objectives are expressed. }\end{array}$ \\
\hline Operational & $\begin{array}{l}\text { The metric can be assessed, forecasted, and monitored within budgetary, time, and } \\
\text { labor constraints. }\end{array}$ \\
\hline Transparent & $\begin{array}{l}\text { The relationship between the metric and what is being measured is obvious, so that it } \\
\text { clearly communicates the consequences of a decision and any trade-offs involved in } \\
\text { decisions. }\end{array}$ \\
\hline
\end{tabular}


Bruneau et al. (2003) and Walker and Salt (2006) have identified properties of resilient systems. These properties are described in Table 9 and may be useful in identifying indicators of robustness and rapidity. With respect to engineering resilience, those indicators that describe robustness and rapidity are direct indicators of resilience. Robustness and rapidity can be described using natural, constructed, or proxy metrics. Indicators that describe the adaptability, diversity, modularity, redundancy, resourcefulness, and tightness of feedbacks are indicative of robustness and rapidity, but the extent of their correlation with robustness and rapidity tends to be uncertain. Therefore, they are indirect indicators of engineering resilience. These attributes of resilient systems can be described using natural, constructed, or proxy metrics.

Table 9. Properties of resilient systems.

\begin{tabular}{|c|c|c|}
\hline System Property & Description & Example \\
\hline Adaptability & $\begin{array}{l}\text { Capacity to change as the surrounding environment } \\
\text { changes while still maintaining functionality } \\
\text { (Walker and Salt 2006). }\end{array}$ & $\begin{array}{l}\text { The ability to contract for dredging } \\
\text { services and restore pre- } \\
\text { disturbance limiting depth in a } \\
\text { navigation channel on short } \\
\text { notice. }\end{array}$ \\
\hline Diversity & $\begin{array}{l}\text { Variety in the number of species, people, and } \\
\text { institutions that exist in a social-ecological system } \\
\text { (Walker and Salt 2006). }\end{array}$ & $\begin{array}{l}\text { The vegetation in a wetland } \\
\text { includes a large number of } \\
\text { different species that respond } \\
\text { differentially to different types of } \\
\text { stressors. }\end{array}$ \\
\hline Modularity & $\begin{array}{l}\text { The extent to which the components and processes } \\
\text { that make up a system are dependent upon each } \\
\text { other to maintain function (Walker and Salt 2006). }\end{array}$ & $\begin{array}{l}\text { There are multiple navigable } \\
\text { routes to a single port or harbor. }\end{array}$ \\
\hline Rapidity & $\begin{array}{l}\text { The time required to restore system performance to } \\
\text { a pre-disturbance level. The capacity of a system to } \\
\text { meet priorities and achieve goals in a timely } \\
\text { manner to contain losses and avoid future } \\
\text { disruption (Bruneau et al. 2003) }\end{array}$ & $\begin{array}{l}\text { The length of time required to } \\
\text { remove sediment from a naviga- } \\
\text { tion channel following a storm. }\end{array}$ \\
\hline Redundancy & $\begin{array}{l}\text { Extent to which elements, systems, or other units of } \\
\text { analysis exist that are substitutable (i.e., capable of } \\
\text { satisfying functional requirements in the event of } \\
\text { disruption, degradation, or loss of functionality } \\
\text { (Bruneau et al. 2003, Walker and Salt 2006)). }\end{array}$ & $\begin{array}{l}\text { The availability of excess pumping } \\
\text { capacity to remove water } \\
\text { accumulated from rainfall and } \\
\text { storm surge from a protected } \\
\text { area. }\end{array}$ \\
\hline Resourcefulness & $\begin{array}{l}\text { The capacity to identify problems and priorities, and } \\
\text { mobilize resources when the function of some } \\
\text { element, system, or other unit of analysis is } \\
\text { disrupted. Resourcefulness may also be concept- } \\
\text { tualized as the ability to apply material (i.e., money, } \\
\text { physical, technological, and informational) and } \\
\text { human resources to meet goals (Bruneau et al. } \\
\text { 2003). }\end{array}$ & $\begin{array}{l}\text { The ability to monitor off-shore } \\
\text { hurricanes and predict points of } \\
\text { landfall during hurricane season. } \\
\text { The ability to move emergency } \\
\text { equipment to the sites where it is } \\
\text { needed most, as soon as that } \\
\text { need is determined. }\end{array}$ \\
\hline
\end{tabular}




\begin{tabular}{|l|l|l|}
\hline System Property & Description & Example \\
\hline Robustness & $\begin{array}{l}\text { The ability of elements, systems, and other units of } \\
\text { analysis to withstand a given level of stress or } \\
\text { demand without suffering degradation or loss of } \\
\text { function (Bruneau et al. 2003). }\end{array}$ & $\begin{array}{l}\text { The ability of a jetty to weather a } \\
\text { coastal storm without disrupting } \\
\text { its function. }\end{array}$ \\
\hline Feedbacks & $\begin{array}{l}\text { How quickly and strongly the consequences of a } \\
\text { change in one part of the system are felt and } \\
\text { responded to in other parts of the system (Walker } \\
\text { and Salt 2006). }\end{array}$ & $\begin{array}{l}\text { The length of time between initial } \\
\text { awareness of a hazard (hurricane } \\
\text { landfall prediction) and the } \\
\text { evacuation of at-risk populations. }\end{array}$ \\
\hline
\end{tabular}




\section{Discussion}

This report has introduced a structured way of thinking about the engineering resilience of integrated coastal systems to disturbance events. A disturbance is a transient excursion of boundary forces acting on system components and processes in ways that may impair system function. Resilience has been defined as the joint probability of meeting objectives with respect to functional performance and recovery, given the severity of the event. Robustness and rapidity objectives are established considering the potential losses associated with functional impairment and recovery. Robustness and rapidity objectives may be made more or less stringent to ensure a positive expected net benefit from management of the system. The resilience of components and processes is then rolled up into an overall measure of resilience for the subsystem and the system as a whole. This report has also described the meaning of the term "evolution of resilience.” Resilience evolves over longer time scales in response to an evolutionary force. Evolutionary forces are gradual changes in boundary conditions over time scales that are much longer than the time scales over which the disturbance of interest occurs. Evolutionary forces may also affect the functional performance of the system.

Engineering resilience is a desirable quality in an ICS because these systems are designed for consistency and predictability in functional performance. In a system that is more resilient to disturbances, the components and processes that support that system's function have lower probabilities of failure, the potential consequences of failure are lower, and the time required to recover system function following a disturbance is reduced (Bruneau and Reinhorn 2007). The USACE has the opportunity to influence the engineering resilience of an ICS through planning, pre-construction engineering and design, operations and maintenance, and asset management decisions. USACE may have less opportunity to influence ecological or community resilience. Therefore, less emphasis has been placed on these forms of resilience in this report. Another reason that less attention has been given to ecological and community resilience in this report is that these concepts are much less amenable to quantification, as described in the introduction. However, this should not be interpreted to mean that these concepts are somehow less important than engineering resilience. USACE 
might also consider how its actions influence the ecological and community resilience of ICSs.

This section focuses on how information about resilience might be used within the USACE to support decision making. This discussion begins by comparing the advantages and disadvantages of probabilistic measures and non-probabilistic indicators. This is followed by an examination of the various ways that a probabilistic measure or non-probabilistic indicators of resilience might be used within USACE as a project and system-level performance metric. For example, information about the resilience of an ICS might be used within the agency for programmatic and budgetary purposes as well as for planning, pre-construction engineering and design, operations and maintenance, and asset management. This section concludes with a summary of gaps in knowledge about resilience and integrated coastal systems that may need to be resolved before information about resilience can be used to support decision making.

\section{Advantages and disadvantages of probabilistic and non-probabilistic approaches}

The probabilistic approach to analyzing system resilience requires a decomposition of the ICS into a set of components and processes and an analysis of the resilience of each component or process. Performance measures, performance objectives, and fragility curves are needed for each component or process function, as is information about interdependency. A performance function must then be developed to evaluate whether or not robustness and rapidity objectives can be met within the system. This analysis can become relatively complex and will tend to require a high level of detailed knowledge about the system and a high level of training and skill to execute effectively. Non-probabilistic indicators of resilience that directly or indirectly assess the ability of the system to remain functional during a disturbance and to recover the pre-disturbance performance level following a disturbance have been described as an alternative to probabilistic measures. Advantages and disadvantages of the probabilistic and nonprobabilistic approaches are summarized in Table 10. The following points of comparison are summarized:

\section{- What is the basis for the assessment of resilience?}

Assessments of resilience can be based on models, observations of system performance during and following disturbance events, or apparent characteristics of the system: 
Table 10. Advantages and disadvantages of probabilistic and non-probabilistic approaches.

\begin{tabular}{|c|c|c|}
\hline $\begin{array}{l}\text { Measure of } \\
\text { Resilience }\end{array}$ & Advantages & Disadvantages \\
\hline $\begin{array}{l}\text { Probabilistic } \\
\text { measure }\end{array}$ & $\begin{array}{l}\text { - Provides information about resilience to } \\
\text { disturbances that have not yet been } \\
\text { observed. } \\
\text { - Incorporates explicit information about } \\
\text { robustness and recovery objectives. } \\
\text { - Provides a single characterization of } \\
\text { resilience accounting for both robustness } \\
\text { and rapidity. } \\
\text { - Provides a single measure of resilience } \\
\text { over the full set of potential disturbance } \\
\text { events. } \\
\text { - Provides direct comparisons of different } \\
\text { systems exposed to different types of } \\
\text { disturbances are possible. } \\
\text { - Probabilistic measures provide direct } \\
\text { inputs to risk management decisions. }\end{array}$ & $\begin{array}{l}\text { - Requires detailed information about the } \\
\text { system to implement. } \\
\text { - Requires models to simulate component, } \\
\text { process and system response to } \\
\text { disturbance effectively. } \\
\text { - Requires information on } \\
\text { interdependencies among components and } \\
\text { processes. } \\
\text { - Requires a high level of training and skill } \\
\text { to estimate and interpret. } \\
\text { - Relatively costly and time-consuming to } \\
\text { estimate. }\end{array}$ \\
\hline $\begin{array}{l}\text { Direct } \\
\text { indicator }\end{array}$ & $\begin{array}{l}\text { - Direct indicators are unambiguously } \\
\text { linked to system performance. } \\
\text { - Based on empirical data on system } \\
\text { response or models of system response. } \\
\text { - Does not require a high level of training } \\
\text { or skill to implement or interpret. } \\
\text { - Incorporates explicit information about } \\
\text { management objectives. } \\
\text { - Easy to communicate to decision makers } \\
\text { and stakeholders. }\end{array}$ & $\begin{array}{l}\text { - Evaluation of direct indicators requires } \\
\text { empirical data on or models of system } \\
\text { response and recovery. } \\
\text { - Provides information about resilience to a } \\
\text { single event rather than the full set of } \\
\text { potential disturbance events. } \\
\text { - May be difficult to interpret the indicator } \\
\text { in a way that is useful for decision } \\
\text { making. } \\
\text { - Indicator is non-probabilistic and, } \\
\text { therefore, cannot be used as a direct input } \\
\text { to risk-based decisions. }\end{array}$ \\
\hline $\begin{array}{l}\text { Indirect } \\
\text { indicator }\end{array}$ & $\begin{array}{l}\text { - Based on apparent characteristics of the } \\
\text { system that can be measured and } \\
\text { monitored over time. } \\
\text { - Does not require observations of system } \\
\text { performance during and following a } \\
\text { disturbance. } \\
\text { - Easy to communicate to decision makers } \\
\text { and stakeholders. }\end{array}$ & $\begin{array}{l}\text { - Provides information about resilience to a } \\
\text { single event rather than the full set of } \\
\text { potential disturbance events. } \\
\text { - May be difficult to interpret the indicator } \\
\text { in a way that is useful for decision } \\
\text { making. } \\
\text { - Indicator is non-probabilistic and, } \\
\text { therefore, cannot be used as a direct input } \\
\text { to risk-based decisions. } \\
\text { - The association between an indirect } \\
\text { indicator and robustness and rapidity may } \\
\text { be unclear. } \\
\text { - Weak link to management objectives for } \\
\text { system performance, robustness, and } \\
\text { rapidity. }\end{array}$ \\
\hline
\end{tabular}


o Probabilistic measures of resilience are based on models of component and process functions, which must then be related to performance of the ICS subsystem. The advantage of using models is that they can simulate performance under many different levels of disturbance severity. The disadvantage of relying on models is that a model of component or process function must be available or developed to simulate performance.

o Direct indicators can be based on modeling results or, alternatively on direct observations of the system during and following disturbance events. If direct observations of the system are used, the advantage of this approach is that many of the uncertainties associated with using models are eliminated. However, the primary disadvantage is that robustness and rapidity can only be assessed for those disturbances that can be observed directly or for which historical records are available.

o Indirect indicators are based on information about characteristics of a system that are believed to be correlated with robustness or rapidity. These indicators have the advantage that they can be measured, counted, or otherwise assessed at any time without observing how a system actually responds to a disturbance. However, their greatest weakness is uncertainty in how strongly these characteristics are correlated with robustness and/or rapidity.

- How easily is the measure or indicator assessed? Probabilistic measures and indicators differ in terms of how much information is required to develop the assessment, how frequently opportunities to obtain the information arise, and how much training and skill are required to execute the analysis:

o Probabilistic measures of resilience require a great deal of information about the system, including information about functional interdependencies among components and processes that may be difficult to obtain. Probabilistic measures also require a relatively high level of training to understand and execute effectively, both in terms of knowledge about coastal systems and knowledge about uncertainty and risk analysis. The time and cost required to develop probabilistic measures of resilience is likely to greatly exceed the time and cost required to develop non-probabilistic indicators of resilience. However, probabilistic measures of resilience have the advantage that, because they are based on models, assessments can 
be developed at any time and for any level of event severity, regardless of whether or not a disturbance event of that severity has actually occurred in the past.

o Direct indicators of resilience are based on models or observations of how the system performs during and following a disturbance. If models are used as the basis for the assessment, these can be developed at any time, regardless of whether or not the disturbance has occurred in the past. However, as with probabilistic measures of resilience, models capable of simulating system performance are needed in the first place and a high level of training and skill are required to implement the model effectively. If direct observations of system performance are used as the basis for the assessment, these observations must coincide with the occurrence of disturbance events, although the availability of historical records may alleviate this burden. However, it will only be possible to develop assessments of resilience for those events that have occurred in the past.

o Indirect indicators can be developed whenever it is possible to obtain information on system characteristics that are believed to be associated with the resilience of the ICS. There may be many such indicators and the ease with which information about these indirect indicators can be developed will vary greatly, as will the time required to develop the information and the amount of training and skill needed to complete the assessment.

- How well does the measure or indicator of resilience serve as a communication tool? Probabilistic measures and non-probabilistic indicators differ in terms of how well they can communicate information about ICS resilience to decision makers. Measures and indicators that are closely related to system performance objectives and plainly communicate information about how the system will perform and recover following a disturbance are the best communication tools. If the strength of association with system performance objectives is weak or its meaning is ambiguous, the measure or indicator will not be an effective communication tool.

o Probabilistic measures of resilience are strongly related to performance objectives and incorporate information about robustness and rapidity objectives for a system. However, because they are joint probabilities, they do not communicate how well the system would perform or how quickly pre-disturbance performance 
would be recovered. This information is developed in the course of an analysis of resilience and can be communicated to decision makers separately. The meaning of a probabilistic measure of resilience is unambiguous. However, some decision makers may not have sufficient training to interpret this information correctly or be able to understand its limitations and use this information in decision making.

o Direct indicators of robustness and rapidity are strongly associated with system performance, their meaning is unambiguous, and they can be easily understood by decision makers. However, if substantial uncertainties are involved in assessing these indicators, this information should also be communicated to decision makers. In addition, direct indicators do not yield a probability of acceptable performance that might be used in risk-based decision making.

o Indirect indicators of robustness and rapidity will vary greatly in terms of the strength of their association with the robustness and rapidity of the system. In general, the weaker the association, the more difficult these indicators will be to interpret and the more uncertainty will be attached to these indicators when used in decision making. Indirect indicators may be ambiguous and will almost certainly be interpreted differently by different decision makers.

\section{- Does the measure or indicator incorporate explicit} information about robustness and recovery objectives? For economic reasons, ICS management objectives are likely to vary from system to system. More stringent performance objectives may be justified for systems that are expensive to restore to functionality or for which a loss of functionality would result in large opportunity costs. Similarly, more stringent performance objectives may be justified for disturbance events that have lower severity and higher frequency of occurrence. Therefore, robustness and recovery objectives should be developed for each system considering the frequency and severity of disturbance events, the economic cost of impaired ICS functions, and the economic cost of preventing and restoring functional performance.

o Probabilistic measures of resilience incorporate information about management objectives in the form of criteria for determining what level and duration of performance impairment are acceptable given 
the severity of the event. Resilience is the joint probability of acceptable performance based on these criteria.

o Direct indicators of robustness and rapidity incorporate information about management objectives. However, the indicators provide no information about uncertainty in the level of performance that may be realized or the duration of performance impairment.

o Indirect indicators may be difficult to relate to ICS management objectives for robustness and rapidity because of the uncertain relationship between the characteristics of the system that are assessed and system performance.

- Does the measure or indicator provide a single, interpretable scale that is integrated over the robustness and rapidity dimensions? A measure of resilience provides information about the degree of resilience on an interpretable scale. An analysis of resilience that treats robustness and rapidity independently cannot be resolved in an interpretable scale that provides information about the degree of resilience.

o Probabilistic measures of resilience describe the joint probability of meeting both robustness and rapidity criteria. Probability provides a single, unified scale for describing the degree of resilience and enables ICSs to be compared in terms of their resilience.

o Direct indicators of robustness describe system performance. Direct indicators of rapidity describe the length of time required to restore pre-disturbance performance. This approach does not yield a common unifying scale for describing the degree of resilience in an ICS because robustness and rapidity are addressed separately. Comparisons of robustness across different systems will be very difficult if different functional performance measures are used in those systems.

o Indirect indicators of resilience may be correlated with either one or both dimensions of resilience. However, the strength of the correlation with the robustness and rapidity dimensions may be unequal, leading to difficulties in interpretation of the indicator. Similarly, differences in the correlation of indirect indicators with robustness and rapidity in different systems will make it difficult to compare resilience in those systems. 
- Does the measure or indicator provide a single characterization of resilience over all potential disturbance events, including those that have not yet occurred? Measures and indicators of resilience should provide information to inform decisions about reducing the risks of functional impairment. Such decisions require insights into how the system will perform in the face of events that may occur in the future, but have not yet occurred. Models of the system and its components and processes will be needed to simulate the effects of events that may occur in the future, but have not yet occurred.

o Probabilistic measures of resilience are based on models of how the system will perform as boundary conditions change. Because potential disturbance events can be simulated using models, probabilistic measures of resilience can include information on potential disturbance events that have not yet occurred.

o Direct indicators of robustness and rapidity can be based on models or observations. If assessments are based on observations, then resilience can only be assessed with respect to those disturbance events that have occurred in the past. If assessments are based on models, then potential disturbance events can be simulated.

o Indirect indicators of robustness and rapidity do not include information about the severity and probability of disturbance events.

- Can the measure or indicator be used to compare the resilience of different types of systems to different types of disturbances? Measures of resilience are needed that can be used to compare the resilience of two or more systems that may be exposed to different types of hazards. These comparisons are most straightforward if the same scale is used in assessing the degree of resilience in each system.

o Probabilistic measures of resilience can be used to compare the resilience of different types of systems that are exposed to different types of hazards because probability provides a unifying scale. The probability scale could be interpreted as the degree of resilience.

o Direct indicators are more difficult to use in making comparisons across different types of systems exposed to different types of hazards. There is no unified measure of the degree of resilience because robustness and rapidity are addressed separately. In 
addition, comparisons of the robustness of two or more systems will be difficult if the functional performance metrics differ from system to system.

o Indirect indicators are even more difficult to use in making comparisons across systems than direct indicators. Each system is unique and the correlation between the characteristic being assessed and the robustness or rapidity of the system will likely be very different in each system.

\section{- How useful is the measure or indicator in decision making?} Information about resilience may be used to inform decisions in planning, pre-construction engineering design, operations and maintenance, and asset management. For non-risk-based decisions, a common scale that captures information about the degree of resilience in a system will be needed to inform any decision involving more than one ICS. Risk-based decisions require information about the probability of acceptable performance to use in conjunction with information about the cost of performance impairment and recovery and the cost of making the system more robust.

o Probabilistic measures of resilience can be used in conjunction with information about the cost of performance impairment and the cost of restoring system performance to make risk-based decisions about investments to improve resilience and reduce risk.

o Direct indicators of robustness and rapidity do not provide sufficient information for risk-based decisions, but may be useful in making non-risk-based decisions about similar systems.

o Indirect indicators of robustness and rapidity do not provide sufficient information for risk-based decisions. It seems unlikely that indirect indicators would provide sufficient information to make comparisons across different types of systems on a large scale, particularly if those systems are exposed to different types of hazards.

\section{How could USACE use information about resilience?}

Resilience is a property of ICSs that can be evaluated quantitatively. It has been proposed that measures of resilience could be used to inform decisions within USACE. The list of potential uses for information about resilience is constrained only by the imagination. This discussion considers potential uses of information about resilience at the project level and at the program 
level. Analyses of resilience can also be used simply to learn more about an ICS or to identify those components or processes that may be most vulnerable to disturbances. At the project level, information about resilience might be used to inform decisions at all stages of the life cycle, including planning, pre-construction engineering and design, operations and management, and asset management.

- Planning: At the planning stage, alternatives for a proposed project are evaluated based on a set of criteria, such as national and regional economic development benefits and life-cycle project costs. A probabilistic measure of resilience could be used to estimate the expected cost of functional performance impairment and recovery. This estimate could then be considered in estimating the project's economic benefits over the planning horizon. In selecting a project alternative, the objective is not to maximize resilience, but rather to select an alternative in which the investments in making the project resilient are justified by the future stream of benefits.

- Pre-construction: During pre-construction engineering and design, information about resilience could be used to judge the viability of proposed projects based on an adopted criteria for resilience in federal projects. Proposed ICS projects or systems that do not demonstrate a sufficient level of resilience might be rejected pending improvements in engineering or design. By showing that an ICS project or system meets a resilience objective, USACE can communicate to the Administration, the public, and the Congress that it is making wise decisions with regard to investments and adaptation to climate change.

- Operations and maintenance: Assessments of resilience can be used to judge how well projects are performing in terms of resilience and whether or not resilience objectives have been met. The information can be used to evaluate the need for improvements and to guide the engineering and design of future projects elsewhere. Where economic constraints mean that there is less interest in constructing new projects and more interest in rehabilitating existing projects, information from a probabilistic analysis of resilience can be used to guide those investments by identifying which components may be the weakest link in achieving ICS investment objectives.

- Asset management: Resilience could be considered as a factor in decisions regarding the decommissioning, deconstruction, or replacement of assets within an ICS. A probabilistic analysis of 
resilience could be used to diagnose the assets that may be causing low levels of resilience within an ICS because of poor design or because of changes that may have occurred in environmental forces during the life-cycle of the project.

Information about the resilience of existing ICS projects could be used as one basis for programmatic decisions that involve the allocation of resources for capital investment or for operations and maintenance. For example, resources could be allocated to those projects that demonstrate the most need for improvements in resilience. Alternatively, resources could be allocated only to those projects demonstrating a sufficient level of resilience, creating incentives for project sponsors to invest private funds in improving the resilience of those systems.

Before adopting resilience as a criterion in decision making, consideration should be given to the costs of developing an analysis and the value of that information in decision making. Different levels of analysis may be appropriate for the various decision environments depending upon the complexity of the project, the stakes involved in the decision, and how much accuracy is needed in the results to inform the decision. Information about resilience will bring value in the decision-making process only if that information has the potential to change the decision. Consideration must be given to the costs of developing the information and the benefits of using that information in terms of direct economic value realized in the project or opportunity costs avoided. If the costs exceed the benefits, or the information would not alter decisions about the program or project, assessments of resilience have the potential to become meaningless exercises that bog down the decision-making process. Particularly when the costs of a probabilistic analysis of resilience are expected to be high, screening-level analyses should be completed before undertaking a detailed probabilistic analysis to assess the potential value of information for the decision.

Probabilistic analyses are often useful, but they can be challenging to undertake, the results can be difficult to verify, and there may be considerable expense involved in completing an analysis. In contrast, nonprobabilistic indicators may be relatively cheap, but they may tend to be less accurate and they do not provide the information needed for risk-informed decision making. Lund (2008) describes three conditions under which probabilistic analyses undertaken to identify an optimal decision alternative 
may be sub-optimal. These conditions are worth considering when evaluating the pros and cons of probabilistic and non-probabilistic approaches. Probabilistic analyses may be sub-optimal when: 1) the expected net benefit of the optimal alternative and the alternative that would have been chosen using an alternate approach is less than the difference in the cost of implementing the two analytical approaches; 2) the decision problem is not properly formulated and solved using probabilistic methods, the results are not accurately interpreted by analysts, or the decision makers cannot understand the results of the analysis; and 3) the results of a risk analysis do not lead to an alternative that is substantially better than one that would have been selected using a non-probabilistic approach. 


\section{References}

Adger, W. N., T. P. Hughes, C. Folke, S. R. Carpenter, J. Rockstrom. 2005. Socialecological resilience to coastal disasters. Science 319 (2005): 1036-9.

Brand, F. S., and K. Jax. 2007. Focusing the meaning(s) of resilience: Resilience as a descriptive concept and a boundary object. Ecology and Society 1(1): 23 [online] URL: http://www.ecologyandsociety.org/vol12/iss1/art23/.

Bruneau, M., and A. Reinhorn. 2007. Exploring the concept of seismic resilience for acute care facilities. Earthquake Spectra 23(1):41-62.

Bruneau, M., S. E. Chang, R. T. Eguchi, G. C. Lee, T. D. O’Rourke, A. M. Reinhorn, M. Shinozuka, K. Tierney, W. A. Wallace, and D. von Winterfeldt. 2003. A framework to quantitatively assess and enhance the seismic resilience of communities, Earthquake Spectra 19(4): 733-752.

Chang, S. E., and M. Shinozuka. 2004. Measuring improvements in the disaster resilience of communities. Earthquake Spectra 20(3): 739-755.

Chang, S. E., C. Pasion, K. Tatebe, and R. Ahmad. 2008. Linking lifeline infrastructure performance and community disaster resilience: Models and multi-stakeholder processes. Technical Report MCEER-08-0004. New York: Multidisciplinary Center for Earthquake Engineering Research, State University of New York at Buffalo.

Dale, V. H., and S. C. Beyeler. 2001. Challenges in the development and use of ecological indicators. Ecological Indicators 1(2001): 3-10.

Fagre, D. B., C. D. Allen, C. Birkeland, F. S. Chapin, P. M. Groffman, G. R. Guntenspergen, A. K. Knapp. 2009. CCSP 2009: Thresholds of climate change in ecosystems. Washington, DC: U.S. Climate Change Science Program (CCSP) and the Subcommittee on Global Change Research, U.S. Geological Survey, and Department of the Interior.

Fiering, M. B. 1982a. A screening model to quantify resilience. Water Resources Research 18(1): 27-32.

Fiering, M. B. 1982b. Estimates of resilience indices by simulation. Water Resources Research 18(1): 41-50.

Fiering, M. B. 1982c. Estimating resilience by canonical analysis. Water Resources Research 18(1): 51-57.

Gordon, J. E. 1978. Structures. Harmondsworth, UK: Penguin Books.

Gregory, R. S., and R. L. Keeney. 2002. Making smarter environmental management decisions. Journal of the American Water Resources Association 38(6):16011612. 
Haimes, Y. Y. 2004. Risk modeling, assessment, and management. New York: John Wiley \& Sons.

Hashimoto, T., J. R. Stedinger, and D. P. Loucks. 1982a. Reliability, resiliency, and vulnerability criteria for water resource system performance evaluation. Water Resources Research 18(1): 14-20.

Hashimoto, T., D. P. Loucks, and J. R. Stedinger. 1982b. Robustness of water resources systems. Water Resources Research 18(1): 21-26.

Holling, C. S. 1973. Resilience and stability of ecological systems. Annual Review of Ecology and Systematics 4(1973): 1-23.

Holling, C. S. 1996. Engineering resilience versus ecological resilience. In Engineering within ecological constraints, ed. P. C. Schultz, 31-44. Washington, DC: The National Academies Press.

Keeney, R. L., and H. Raiffa. 1993. Decisions with multiple objectives: Preferences and value tradeoffs, Cambridge, UK: Cambridge University Press, 569.

Keeney, R. L., and R. S. Gregory. 2005. Selecting attributes to measure the achievement of objectives. Operations Research 53(1): 1-11.

Klein, R. J. T., R. J. Nichols, and F. Thomalla. 2003. Resilience to natural hazards: How useful is this concept? Environmental Hazards 5(2003): 35-45.

Lund, J. R. 2008. A risk analysis of risk analysis. Journal of Contemporary Water Research and Education 140(2008): 53-60.

Maier, H. R., B. J. Lence, B. A. Tolson, and R. O. Foschi. 2001. First order reliability method for estimating reliability, vulnerability, and resilience. Water Resources Research 37(3): 779-90.

Martin-Breen, P., and J. M. Anderies. 2011. Resililence: A Literature Review (draft). White paper prepared for the Rockefeller Foundation, New York, N.Y. (http://www.rockefellerfoundation.org/news/publications, Accessed May 6, 2012).

McDaniels, T., S. Chang, D. Cole, J. Mikawoz, H. Longstaff. 2008. Fostering resilience to extreme events within infrastructure systems: Characterizing decision contexts for mitigation and adaptation. Global Environmental Change 18(2008): 310318.

McKay, S. K., B. A. Pruitt, M. Harberg, A. P. Covich, M. A. Kenney, and J. C. Fischenich. 2010. Metric development for environmental benefits analysis. EBA Technical Notes Collection ERDC TN-EMRRP-EBA-4. Vicksburg, Mississippi: U.S. Army Engineer Research and Development Center (http://cw-environment.usace.army. mil/eba/).

Melchers, R. E. 1999. Structural reliability analysis and prediction ( $2^{\text {nd }}$ ed.). West Sussex, England: John Wiley \& Sons, 437.

Moddares, M., M. Kaminskiy, V. Krivtsov. 2010. Reliability engineering and risk analysis: A practical guide ( ${ }^{\text {nd }}$ ed.). Boca Raton, FL: CRC Press, 454. 
Moy, W. S., J. L. Cohon, and C. S. ReVelle. 1986. A programming model for analysis of the reliability, resilience, and vulnerability of a water supply reservoir. Water Resources Research 22(4): 489-498.

National Research Council (NRC). 2009. Ecological impacts of climate change. Washington DC: The National Academies Press.

Norris, F. H., S. P. Stevens, K. F. Wyche, and R. L. Pfefferbaum. 2008. Community resilience as a metaphor, theory, set of capacities, and strategy for disaster readiness. American Journal of Community Psychology 41(1-2): 127-150.

O'Rourke, T. D. 2007. Critical infrastructure, interdependencies, and resilience. The Bridge 37(1):22-29.

Pearl, J. 1988. Probabilistic reasoning in intelligent systems. San Francisco, CA: Morgan Kauffman Publishers, p.552.

Reed, D. A., K. C. Kapur, and R. D. Christie. 2009. Methodology for assessing the resilience of networked infrastructure. IEEE Systems 3(2):174-180.

Reichert, P., M. Borsuk, M. Hostmann, S. Schweizer, C. Sporri, K. Tockner, and B. Truffer. 2007. Concepts of decision support for river rehabilitation, Environmental Modeling and Software 22(2007):188-201.

Renschler, C. S., A. E. Frazier, L. A. Arendt, G. Cimellaro, A. M. Reinhorn, and M. Bruneau. 2010. A framework for defining and measuring resilience at the community scale: The PEOPLES resilience framework. Technical Report MCEER-10-0006. New York: Multidisciplinary Center for Earthquake Engineering Research, State University of New York at Buffalo.

Rosati, J. D., and N. C. Kraus. 2009. Sea level rise and consequences for navigable coastal inlets. Shore \& Beach 77(4):1-7.

Schultz, M. T., B. P. Gouldby, J. D. Simm, and J. L. Wibowo. 2010. Beyond the factor of safety: Developing fragility curves to characterize system reliability. ERDC SR10-1. Vicksburg, MS: US Army Engineer Research and Development Center, 62.

Simonovic, S. P., and L. Li. 2004. Sensitivity of the red river basin flood protection system to climate variability and change. Water Resources Management 18(2): 89-110.

Slocombe, D. S. 1998. Defining goals and criteria for ecosystem-based management. Environmental Management 22(4):483-493.

Stewart, T. R., and A. Bostrom. 2002. Extreme event decision-making. Workshop Report, Center for Policy Research, Rockefeller College of Public Affairs and Policy, University at Albany. (Accessed December 15, 2010 http://www.albany. edu/cpr/xedm).

Suter, G. W. 2001. Applicability of indicator monitoring to ecological risk assessment. Ecological Indicators 1(2001):101-112. 
Titus, J. G., E. K. Anderson, D. R. Cahoon, D. B. Gesch, S. K. Gill, B. T. Gutierrez, E. R. Thieler, and S. J. Williams. 2009. CCSP 2009: Coastal sensitivity to sea-level rise: A focus on the Mid-Atlantic Region. Washington, DC: U.S. Climate Change Science Program and Subcommittee on Global Change Research and U.S. Environmental Protection Agency, 320.

U.S. Army Corps of Engineers (USACE). 2000. Planning guidance notebook. ER-1105-2100. Washington, DC.

Walker, B., and D. Salt. 2006. Resilience thinking: Sustaining ecosystems and people in a changing world. Washington, DC: Island Press, 174.

Walker, B., L. Gunderson, A. Kinzig, C. Folke, S. Carpenter, and L. Schultz. 2006. A handful of heuristics and some propositions for understanding resilience in social-ecological systems. Ecology and Society 11(1):13. [Online] URL: http://www.ecologyandsociety.org/vol11/iss1/art13/.

Wang, C., and J. M. Blackmore. 2009. Resilience concepts for water resource systems. Journal of Water Resources Planning and Management 137(6): 528-36.

Zhou, H., J. Wang, J. Wan, and H. Jia. 2010. Resilience to natural hazards: A geographic perspective. Natural Hazards 53(1): 21-41. 


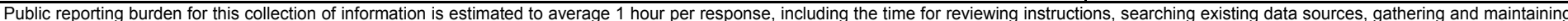

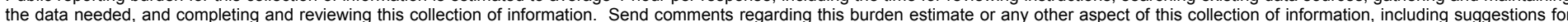

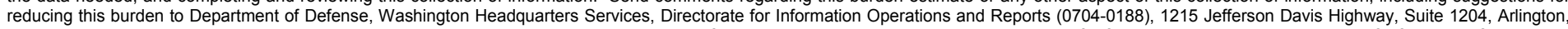

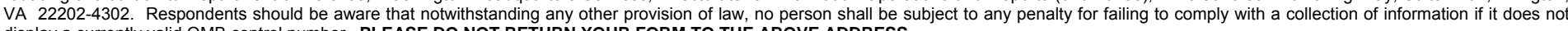
display a currently valid OMB control number. PLEASE DO NOT RETURN YOUR FORM TO THE ABOVE ADDRESS.

\begin{tabular}{c|c}
$\begin{array}{l}\text { 1. REPORT DATE (DD-MM-YYYY) } \\
\text { August } 2012\end{array}$ & $\begin{array}{c}\text { 2. REPORT TYPE } \\
\text { Final report }\end{array}$ \\
\hline
\end{tabular}

\section{TITLE AND SUBTITLE}

The Quantification and Evolution of Resilience in Integrated Coastal Systems

DATES COVERED (From - To)

5a. CONTRACT NUMBER

5b. GRANT NUMBER

5c. PROGRAM ELEMENT NUMBER

\section{AUTHOR(S)}

Martin T. Schultz, S. Kyle McKay, and Lyndell Z. Hales

5d. PROJECT NUMBER

5e. TASK NUMBER

5f. WORK UNIT NUMBER

\section{PERFORMING ORGANIZATION NAME(S) AND ADDRESS(ES)}

8. PERFORMING ORGANIZATION REPORT

Environmental Laboratory

U.S. Army Engineer Research and Development Center NUMBER

3909 Halls Ferry Rd., Vicksburg, MS 39180-6199;

ERDC TR-12-7

Coastal and Hydraulics Laboratory

U.S. Army Engineer Research and Development Center

3909 Halls Ferry Rd., Vicksburg, MS 39180-6199

9. SPONSORING I MONITORING AGENCY NAME(S) AND ADDRESS(ES)

U.S. Army Corps of Engineers

Washington, DC 20314-1000

10. SPONSOR/MONITOR'S ACRONYM(S)

11. SPONSOR/MONITOR'S REPORT NUMBER(S)

\section{DISTRIBUTION I AVAILABILITY STATEMENT}

Approved for public release; distribution is unlimited.

\section{SUPPLEMENTARY NOTES}

\section{ABSTRACT}

Integrated coastal systems are designed, constructed, and maintained to achieve navigation, storm damage reduction, and ecosystem restoration objectives. This report develops a generally applicable method to quantify the resilience of integrated coastal systems to disturbances such as coastal storms. In general, resilience is an ambiguous term that can mean different things in different contexts. This report emphasizes engineering resilience, which is the propensity of a system to resist functional impairments as a result of a disturbance and to recover a pre-disturbance level of functional performance following a disturbance. This report describes how this property of integrated coastal systems can be quantified in probabilistic terms, and how the resilience of a system can evolve over time in response to gradual changes in boundary conditions that occur over time scales that are much longer than the disturbance of interest, such as gradual changes in mean sea level. Coastal system processes that are influenced by sea level rise and may affect the resilience of integrated coastal systems are identified. The advantages and disadvantages of probabilistic and non-probabilistic indicators of resilience are discussed.

\begin{tabular}{|c|c|c|c|c|c|}
\hline \multicolumn{2}{|c|}{$\begin{array}{l}\text { 15. SUBJECT TERMS } \\
\text { Engineering resilience } \\
\text { Infrastructure networks }\end{array}$} & $\begin{array}{l}\text { Integrated coastal } \\
\text { Navigation } \\
\text { Reliability }\end{array}$ & stems & \multicolumn{2}{|c|}{ Storm damage reduction } \\
\hline \multicolumn{3}{|c|}{ 16. SECURITY CLASSIFICATION OF: } & $\begin{array}{l}\text { 17. LIMITATION } \\
\text { OF ABSTRACT }\end{array}$ & $\begin{array}{l}\text { 18. NUMBER } \\
\text { OF PAGES }\end{array}$ & $\begin{array}{l}\text { 19a. NAME OF RESPONSIBLE } \\
\text { PERSON }\end{array}$ \\
\hline $\begin{array}{l}\text { a. REPORT } \\
\text { UNCLASSIFIED }\end{array}$ & $\begin{array}{l}\text { b. ABSTRACT } \\
\text { UNCLASSIFIED }\end{array}$ & $\begin{array}{l}\text { c. THIS PAGE } \\
\text { UNCLASSIFIED }\end{array}$ & & 76 & $\begin{array}{l}\text { 19b. TELEPHONE NUMBER (include } \\
\text { area code) }\end{array}$ \\
\hline
\end{tabular}

